\title{
Framework for understanding marine ecosystem health
}

\author{
P. Tett ${ }^{1, *}$, R. J. Gowen ${ }^{2}$, S. J. Painting ${ }^{3}$, M. Elliott ${ }^{4}$, R. Forster ${ }^{3}$, D. K. Mills ${ }^{3}$, E. Bresnan ${ }^{5}$, \\ E. Capuzzo ${ }^{3}$, T. F. Fernandes ${ }^{6}$, J. Foden ${ }^{3}$, R. J. Geider ${ }^{7}$, L. C. Gilpin ${ }^{8}$, M. Huxham ${ }^{8}$, \\ A. L. McQuatters-Gollop ${ }^{9}$, S. J. Malcolm ${ }^{3}$, S. Saux-Picart ${ }^{10}$, T. Platt ${ }^{10}$, M.-F. Racault ${ }^{10}$, \\ S. Sathyendranath ${ }^{10}$, J. van der Molen ${ }^{3}$, M. Wilkinson ${ }^{6}$
}

${ }^{1}$ Scottish Association for Marine Science, Scottish Marine Institute, Oban, Argyll PA37 1QA, UK

${ }^{2}$ Agri-Food and Biosciences Institute, Newforge Lane, Belfast BT9 5PX, UK

${ }^{3}$ Centre for Environment, Fisheries and Aquaculture Science, Pakefield Road, Lowestoft, Suffolk NR33 0HT, UK

${ }^{4}$ Institute of Estuarine and Coastal Studies, University of Hull, Hull HU6 7RX, UK

${ }^{5}$ Marine Scotland Science, Marine Laboratory, PO Box 101, 375 Victoria Road, Aberdeen AB11 9DB, UK

${ }^{6}$ School of Life Sciences, Heriot-Watt University, Riccarton, Edinburgh EH14 4AS, UK

${ }^{7}$ School of Biological Sciences, University of Essex, Wivenhoe Park, Colchester CO4 3SQ, UK

${ }^{8}$ School of Life, Sport \& Social Science, Edinburgh Napier University, Edinburgh EH11 4BN, UK

${ }^{9}$ Sir Alister Hardy Foundation for Ocean Sciences, The Laboratory, Citadel Hill, Plymouth PL1 2PB, UK

${ }^{10}$ Plymouth Marine Laboratory, Prospect Place, The Hoe, Plymouth PL1 3DH, UK

\begin{abstract}
Although the terms 'health' and 'healthy' are often applied to marine ecosystems and communicate information about holistic condition (e.g. as required by the Ecosystem Approach), their meaning is unclear. Ecosystems have been understood in various ways, from non-interacting populations of species to complex integrated systems. Health has been seen as a metaphor, an indicator that aggregates over system components, or a non-localized emergent system property. After a review, we define good ecosystem health as: 'the condition of a system that is self-maintaining, vigorous, resilient to externally imposed pressures, and able to sustain services to humans. It contains healthy organisms and populations, and adequate functional diversity and functional response diversity. All expected trophic levels are present and well interconnected, and there is good spatial connectivity amongst subsystems.' We equate this condition with good ecological or environmental status, e.g. as referred to by recent EU Directives. Resilience is central to health, but difficult to measure directly. Ecosystems under anthropogenic pressure are at risk of losing resilience, and thus of suffering regime shifts and loss of services. For monitoring whole ecosystems, we propose an approach based on 'trajectories in ecosystem state space', illustrated with time-series from the northwestern North Sea. Change is visualized as Euclidian distance from an arbitrary reference state. Variability about a trend in distance is used as a proxy for inverse resilience. We identify the need for institutional support for long time-series to underpin this approach, and for research to establish state space co-ordinates for systems in good health.
\end{abstract}

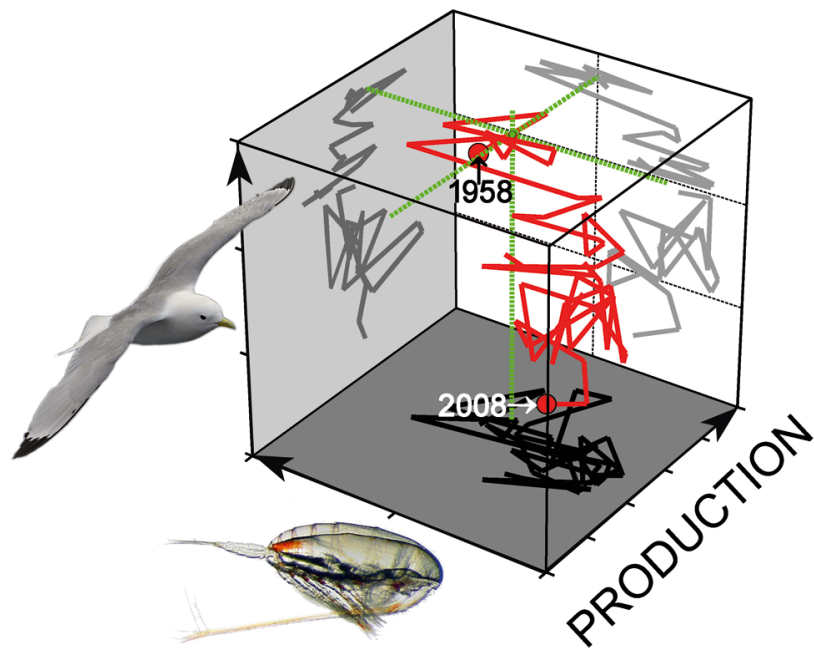

Changes in the northern North Sea, 1958-2008, plotted in a state space defined by the breeding success of kittiwakes, abundance of copepods Calanus spp., and simulated annual primary production.

Image: P. Tett, Photos: R. Gowen (kittiwakes), D. Altin, BioTrix (Calanus spp.)

KEY WORDS: Ecosystem approach · Functional and response biodiversity $\cdot$ Resilience $\cdot$ State space $\cdot$ Regime shift · EU Marine strategy Framework Directive

Resale or republication not permitted without written consent of the publisher 


\section{INTRODUCTION}

Marine ecosystems provide services that lead to societal benefits (Atkins et al. 2011, Barbier et al. 2012). Three common strategies aim to protect these services against anthropogenic pressures. One conserves key organisms and habitats, one protects against disturbance, and one manages resource exploitation. These strategies, however, often neglect the interactions amongst ecosystem components, which in some cases ameliorate pressure effects. In other cases the effects multiply, leading to major disturbances to marine food webs and their use by humans (Fogarty \& Murawski 1998, Jackson et al. 2001, Thurstan \& Roberts 2010).

The need for integrated environmental management is recognized in the 'Ecosystem Approach', and the idea that ecosystems can have an optimal, or healthy, state is beginning to be used as a goal for holistic management, appearing in the marine environmental protection laws of several nations (Table S1 in Supplement 1; all supplements at www.int-res.com/articles/suppl/ m494p001_supp.pdf). However, it has been argued that this idea 'is based on controversial, value-based assumptions that masquerade as science' (Lackey 2001, p. 437). Crucial aspects of health have been presented in terms of metaphors such as those of stability landscapes (Holling 1973, Scheffer et al. 2001) rather than quantitative theories. Proposed holistic methodologies have focussed on the diagnosis of ecosystem pathologies (McLusky \& Elliott 2004) or of undesirable disturbance (Tett et al. 2007), rather than the identification of healthy states or the good status required, for example, by recent EU Directives (Borja et al. 2010). Thus, there is a need to clarify what is meant by 'good ecosystem health' and to develop methods for assessing it.

The present article originated in workshops that had been tasked with developing a sound scientific basis for evaluating the overall status of UK marine waters as required by EU Directives. The article includes a selective review of the literature relevant to ecosystem health, a glossary of key terms (Box 1), and a proposed method for tracking change in the state of marine ecosystems by means of plots in state space. We exemplify the method with data from the North Sea, but believe it to be of general applicability.

\section{REVIEW OF ECOSYSTEM HEALTH}

\section{Nature of ecosystems and aims of management}

Building on Tansley (1935), Lindeman (1942) defined an ecosystem as a 'system composed of physi- cal-chemical-biological processes active within a space-time unit of any magnitude, i.e. the biotic community plus its abiotic environment'. This definition is widely accepted, but a continuing debate concerns the processes. Do they belong to the system or to its components? Is there such a thing as an ecosystem, or is the word merely a label for a human-delineated collection of species and habitats?

Clements $(1916,1936)$ viewed the climax of terrestrial vegetation and its associated animals as 'a complex organism inseparably connected with its climate and often continental in extent' (Clements 1936, p. 253) and possessing ontogeny and phylogeny. Odum (1969) considered that ecological succession culminated in a stabilized ecosystem that maximised biomass, information content, and symbiotic interactions amongst organisms, for a given energy flux. Moss (2008) argued that what he called ecosystems (but which might be better seen as biomes) have evolved, through the natural selection of component species, to become optimal systems for the use of natural resources. In contrast, Gleason (1926) held that terrestrial floras were no more than contingent associations of species that had been selected by the species' environmental requirements and their abilities to disperse. Davis \& Slobodkin (2004) denied that ecosystems existed as 'some integrated entity ... that grows, lives, reproduces and dies, or can be injured or healed' (p. 1). However, Winterhalder et al. (2004) argued that 'biotic communities and ecological systems ... do show a very high degree of integration, or "coherency" in their responses to perturbations of various kinds' (p. 5). If integration exists, a likely explanation is that the biota contribute to the 'ecological theatre' in which they act out the 'evolutionary play' (Hutchinson 1965, Post \& Palkovacs 2009) and so co-evolve (Urban \& Skelly 2006, Johnson \& Stinchcombe 2007).

A related debate concerns stability in ecosystems (Holling 1973, Botkin 1990, Cuddington 2001, Gowen et al. 2012). Are natural systems in balance, and do they tend to return to that balance if perturbed? Or are they intrinsically, and perhaps unpredictably, variable? If pristine ecosystems tend towards a balance of organisms, the goal of environmental protection seems clear: to ensure that (commensurate with human aspirations) communities are assisted towards, or maintained at, their ecological climaxes. If, instead, ecosystems are 'open, complex and dynamic systems that are characteristically transient and unstable' (Spieles 2010, referring to Botkin 1990), as evidence increasingly suggests, then the goal of ecosystem management (as opposed to the 
Box 1. Glossary of key terms relating to ecosystem health. The definitions are those used in this article, unless otherwise qualified. The terms are italicized here, on the first substantive use in the text, and sometimes thereafter

Attractor: a point, or repeating trajectory, in state space to which a system tends

Autopoïetic: [a] self-making or self-maintaining [system] (Varela \& Maturana 1980)

Basin of attraction: 'a region in state space in which the system tends to remain' (Walker et al. 2004, p. 3)

Biodiversity: the phenotypic variability amongst organisms within an ecosystem, and the genetic basis of that variability; cf. 'includes diversity within species, between species and of ecosystems' (Article 2, Convention on Biological Diversity 1992: www.cbd.int/convention/text/default.shtml)

Biome: 'a distinctive combination of plants and animals in a fully developed or climax community ... characterized by a uniform life form of vegetation ... [and including] developmental stages' (Smith 1992), extended to refer to the combination expected under particular ecohydrodynamic conditions

Community: the biota in an ecosystem as distinct from the abiotic environment: i.e. the organisms or species and the trophic links amongst them

Compliance: the ratio of ecosystem state change to (external) pressure change (Fig. 3); the inverse of resistance (to pressure) in the elasticity analogue for resilience (Supplement 6)

Complex: (a system with) sufficient components and interactions to exhibit emergent properties or behaviour, such as non-linearity, homeostasis or autopoïesis, often as a result of nested sub-systems (hierarchy) and feedback loops

Connectance: 'the fraction of all possible links that are realized in a [trophic] network' (Dunne et al. 2002)

Connectivity: refers to spatial links allowing exchanges of individuals or genetic materials amongst meta-populations (Steneck \& Wilson 2010) and of materials and energy amongst habitats or sub-regions within an ecosystem (Dakos et al. 2010)

CPR: Continuous Plankton Recorder, towed by ships of opportunity, to sample plankton (Richardson et al. 2006)

Domain: a defined region in [an ecosystem] state space

DPSIR: acronym for Driver (within society)-Pressure-StateImpact-Response (within society) paradigm, originally by Luiten (1999), updated by Atkins et al. (2011)

Ecohydrodynamic: the physical conditions that select for species and communities in the sea, including water depth, stirring and stratifying tendencies, light penetration, and sediment type (Tett et al. 2007)

Ecological quality ratio: the ratio (between 0 and 1) of the value of an ecological indicator to the value under good conditions

Ecological status: 'an expression of the quality of the structure and functioning of aquatic ecosystems associated with surface waters' (WFD article 2.21 \& Annex V)

Ecosystem: 'the system composed of the physical-chemical-biological processes active within a space-time unit of any magnitude, i.e. the biotic community plus its abiotic environment' (Lindeman 1942, p. 400)
Emergent property: (system) behaviors that cannot be identified through functional decomposition (Johnson 2006) and that are more than the sum of the system's parts, even if explicable in terms of within-system processes (O'Connor \& Wong 2009)

Empirical (conceptualization of ecosystem health): a view of ecosystems as the sum of their parts and hence able to be simulated by mechanistic models; cf. systemic

Empirical model: a model that, even if theory-based, has its parameter values adjusted to best fit simulations to observations; cf. mechanistic model

Endogenous (pressure): generated within the local socialecological system and hence susceptible to local management; in contrast, exogenous pressures are externally generated, and local management can only deal with the consequences (Elliott 2011)

Environment: (1) the abiotic component of an ecosystem (cf. community); (2) what lies outside a given system

ERSEM: European Regional Seas Ecosystem Model, a mechanistic model for marine ecosystems including pelagic and benthic components (Baretta et al. 1995, Baretta-Bekker \& Baretta 1997)

Euclidian distance: the scalar distance between 2 points in state space, calculated from the square root of the sum of squares of the distance along each axis

External description (of a system): properties of the system that characterize its holistic behavior when seen from outside

Functional-group diversity: the sets of species (or components of biodiversity) responsible for ecosystem functions; the sets correspond to benthic guilds, or pelagic lifeforms

Functional-response diversity: biodiversity contributing to different responses to environmental change within a functional group

GES: Good Environmental Status as defined in Article 3.5 of the MSFD, which includes the requirement that 'the structure, functions and processes of the constituent marine ecosystems ... allow those ecosystems to function fully and to maintain their resilience to human-induced environmental change'

GETM: General Estuarine Transport Model (www.getm.eu), a hydrodynamic model designed for use in shelf seas including those with significant intertidal areas

Granularity: the existence, nature and scale of spatial patchiness within an ecosystem

Hierarchy (or hierarchical system): arrangements whereby systems contain subsystems; the emergent properties of the latter contribute to the functioning of the main system, which provides boundary conditions for the subsystems; see also panarchy

Impact: the consequences of ecosystem state change on services to human societies

Integrity (of a system with open boundaries): what maintains the distinctiveness between a system and what is outside it

Internal description (of a system): description in terms of system components and connections, e.g. in terms of a set of state variables

$k$-adapted (species): slow in growth but efficient at resource acquisition; cf. r-adapted 
Box 1 (continued)

Latitude: the greatest amount that a system can change before losing its ability to regain or remain within its original regime (Walker et al. 2004)

Lifeform: a set of species (not necessarily taxonomically related) that play similar roles in ecosystem function; e.g. 'algal silicon users' such as diatoms and silicoflagellates

Mechanistic model: equations and parameters assembled from hypotheses validated in controlled experiments; cf. empirical model

MVA (MultiVariate Analysis): statistical methods for analysing relationships amongst multiple variables; including $P C A$

MSFD: the European Marine Strategy Framework Directive, 2008/56/EC (Official Journal of the European Union [2008] L164:19-40)

Net primary production: formation of organic material by photosynthesis, net of respiratory losses by the same organisms over the time-period considered; in the case of the model-simulated production reported here, photosynthesis and respiration have been integrated over the water column and the day-night cycle

Open: of a system whose boundaries allow inputs and/or outputs

Organization: the types and arrangements or interconnections of the components of a system; cf. vigour

Panarchy: a view of dynamic systems (including ecosystems) as made up of nested or linked subsystems cycling adaptively through development and collapse (Holling 2004)

PCA: Principal Component Analysis, which converts a set of observations of possibly correlated variables into a smaller set of values of linearly uncorrelated variables called 'principal components'

Precariousness: the closeness of a system to: the state at which resilience collapses and a regime shift occurs (Walker et al. 2004); the edge of the 'basin of attraction' (Holling 1973); the edge of the 'cliff' or the 'elastic limit'

Pressure: (1) a link in the DPSIR chain (Luiten 1999), referring to external (anthropogenic) pressure on an ecosystem; (2) the human-altered influxes, outflows and disturbances acting on an ecosystem; in either case, dimensionally undefined

Principal axis (or component): a line drawn through a set of points in a multivariable space so as to minimize the scatter of points about it (typically by minimizing the sum-of-squares of deviations); see $P C A$

Production: the formation of new organic matter at a given trophic level

Qualitative descriptor: 1 of 11 components listed in Annex I of the MSFD as determining the characteristics of GES

$r$-adapted (species): populations capable of rapid increase but inefficient at resource acquisition and liable to high predation; $\mathrm{cf}$. $k$-adapted

Recovery: return towards undisturbed system state as pressure is relaxed; as a component of resilience, the capability of a system to recover

Regime: a bundle of trajectories in system state space

Regime shift: a substantial and persistent change in ecosystem state, condition, or regime that involves many ecosystem components, impacts substantially on services, and in systems theory is explained by a shift to a new attractor
Resilience: 'the capacity of a system to absorb disturbance and reorganize while undergoing change so as to maintain essentially the same functions, structure, identity and feedbacks' (Folke et al. 2004)

Resistance: one of the components of resilience-a measure of difficulty in moving a system within a basin of attraction (Walker et al. 2004); 'the ability of an ecosystem to resist displacement from its reference state during a perturbation stress' (Vallina \& Le Quéré 2011)

Scalar variability: describes the variability of system state about a long-term trend when both are expressed as Euclidian distance using self-standardized variables

SEM (Structural Equation Modelling): a statistical method aimed at eliciting a group of factors, and connections or relations, that best fits a data set (Hox \& Bechger 1998)

(Ecosystem) services: the natural capitals (e.g. fish stocks) and functions (e.g. nutrient cycling) used to benefit human well-being (Atkins et al. 2011)

$S M P$ : (UK) Sea-bird monitoring programme (jncc.defra. gov.uk/page-1550)

Social-ecological system: a linked system of people and nature (Berkes \& Folke 1998); a spatially-bounded region containing an ecosystem and a social system interacting with each other (Tett et al. 2013)

Stability: the tendency for system state to remain near an attractor in state space

Stability landscape: metaphor in which the state of an ecosystem is represented by the position of a ball in an undulating landscape

State: (1) (of a system) a single set of values of a set of state variables sufficient to specify the system's condition uniquely, and plotting to a point in the corresponding state space; (2) 'the state of the environment' (external to human society) as affected by pressure (Luiten 1999)

State space: 'the n-dimensional space of possible locations of [state] variables' (von Bertalanffy 1972, p. 417)

State variable: a quantification of a system property

Status: the condition of (all or part of) an ecosystem assessed relative to a norm

System: 'a set of elements standing in interrelation among themselves and with [their] environment' (von Bertalanffy 1972)

Systemic (conceptualization of ecosystem health): based on a view of ecosystems in accordance with General Systems Theory (von Bertalanffy 1972) and allowing for emergent properties such as resilience; cf. empirical

Trajectory: a sequence of system states plotted in state space

Type-specific reference conditions: in the WFD (Annexes II \& V), the conditions 'normally associated with that [water body] type under undisturbed conditions'

Variability (in state space): has 3 components: semi-cyclical (e.g. associated with seasonal cycles and classed as part of organization); medium-term (about a trend); and long-term (i.e. a trend) (Fig. 1)

Vigour: the ability of a system to maintain or renew its organization by drawing on production (Costanza 1992, vigor)

WFD: the European Water Framework Directive, 2000/ 60/EC (Official Journal of the European Communities [2000] L327:1-72) 
more restricted aims of species and habitat conservation) is harder to define.

A further complication arises if sustainability is seen as a property, or goal, of 'social-ecological systems' (Berkes \& Folke 1998) which have psychological and social dimensions as well as physical existence (Tett et al. 2013). Although both ecological knowledge and preferences for certain states of ecosystems lie in the mental and social worlds, it is important to distinguish social values from ecological facts and theories because they relate to different sorts of 'validity claims' (Habermas 1984). This does not mean that ecological knowledge should only be used instrumentally, to guide actions decided by political processes (Lackey 2001, Davis \& Slobodkin 2004). Our view is that science must inform debate as well as help implement its outcome. Exploring the meaning of 'the health' of ecosystems in terms of their structure and function can show why aiming at 'good ecosystem health' might be good for societies using services from these ecosystems (Atkins et al. 2011).

\section{Ecosystem health as a metaphor}

Metaphors are important in human speech and thought (Pinker 2007). They can help to explain complex things, such as ecosystems, that cannot be adequately described in terms drawn from direct human experience. But they can be ambiguous, misleading when the metaphor is confused with reality, and dangerous when used to guide action.

Human health is an attractive metaphor for ecosystem condition because there is a universal understanding of what it means to be well: to be free from illness, to function well, to be vigorous, to resist and recover from disease, to maintain physical and mental integrity in the face of stress. That is to say, to be in a socially and individually desired condition, defined by a certain range of physiological and psychological states, and to be able to maintain that condition or to recover it after disturbance.

The metaphor has aided ecologists in conceptualizing ecosystem functioning as well as explaining ecosystem condition to the general public and suggesting regulatory goals to government. But it may be dangerous (Lackey 2001, Davis \& Slobodkin 2004) if it allows personal or sectoral values to be intruded into what are claimed as objective assessments. Thus there is a need to consider whether, and to what extent, the components of human health map to those of ecosystem health.

\section{Ecosystem health as an aggregate property}

One approach to a definition is to see health not as a single property of an ecosystem, but as an aggregate of contributions from organisms, species and processes within a defined area. We will refer to this approach as empirical, because, although not without theoretical content, it is based largely on expert observations of ecosystems.

Elliott (2011) listed 6 levels of biological organization, each of which could be termed healthy or unhealthy: cell, tissue, organism, population, community and ecosystem. At the level of organisms, the meaning of 'health' seems unambiguous and identical with that of human physical well-being. At the next level, health concerns the viability of populations or species. At the level of communities and ecosystems the argument becomes more complex. Elliott (2011) described 'community health' as that of an assemblage of organisms that can continue to function in terms of inter-species relationships; and 'ecosystem health' as providing protection against the 'ecosystem pathologies' of Harding (1992) and McLusky \& Elliott (2004) (Table S2 in Supplement 2). Monitoring at this level allows 'detection of things going wrong' against a background of system variability (Elliott 2011). Earlier, Odum (1985) had listed trends expected in 'stressed ecosystems' (Table S3 in Supplement 2), basing these on a conceptual model of ecosystem succession under undisturbed conditions (Odum 1969). We have drawn on these 2 sets of ill-health diagnostics as the basis for the empirical and aggregatable criteria for marine ecosystem health in Table 1.

The first column in Table 1 provides generic criteria. However, there are several types of marine ecosystems, each with their characteristic lifeforms of primary producers, and each linked to particular ecohydrodynamic (Tett et al. 2007) and climatic conditions. Criteria that are applicable across all these types might provide little guidance in managing pressures on a particular type. For example, biodiversity is naturally low in the physically stressed environment of estuaries (Elliott \& Quintino 2007), where biomass can be high as a result of inputs of allochthonous organic matter (Elliott \& Whitfield 2011). In contrast, the oligotrophic waters of the eastern Mediterranean support a high diversity of pelagic micro-algae (Ignatiades et al. 2009). Thus, there is need for the ecological norms of column 2, which link the general criteria to what might be expected in a particular ecosystem under undisturbed conditions.

The European Union Water Framework Directive $(W F D)$ is based on such a norm-based approach 
Table 1. Components of (good) ecosystem health, according to the empirical approach, and as interpreted by EU Directives. Column 3 gives corresponding specifications from Annex V of the EU Water Framework Directive (WFD) for 'high quality status' (which we equate with good health) in 'transitional' and 'coastal' waters. Column 4 refers to the relevant 'qualitative descriptors for determining good environmental status' in Annex I of the Marine Strategy Framework Directive (MSFD), which are expanded by COM (2010)

\begin{tabular}{|c|c|c|c|}
\hline $\begin{array}{l}\text { 1. Generic component of } \\
\text { ecosystem health }\end{array}$ & 2. Ecological norm & 3. WFD ‘high quality status’ & $\begin{array}{l}\text { 4. MSFD 'qualitative } \\
\text { descriptors' }\end{array}$ \\
\hline $\begin{array}{l}\text { Autochthonous primary photo- } \\
\text { synthetic production plus import } \\
\text { of organic matter is roughly in } \\
\text { balance with consumption, so } \\
\text { that there is no large excess of } \\
\text { respiration that might lead to de- } \\
\text { oxygenation nor substantial } \\
\text { export of unconsumed material }\end{array}$ & $\begin{array}{l}\text { Life-form of primary } \\
\text { producer is typical of } \\
\text { ecohydrodynamic type } \\
\text { and production is } \\
\text { within characteristic } \\
\text { range for undisturbed } \\
\text { example of this type }\end{array}$ & $\begin{array}{l}\text { Phytoplankton biomass to be } \\
\text { 'consistent with the type- } \\
\text { specific physico-chemical } \\
\text { condition', macro-algal cover, } \\
\text { and angiosperm abundance to } \\
\text { be 'consistent with undisturbed } \\
\text { conditions'. '[O]xygen balance } \\
\text {... remain[s] within the range ... } \\
\text { normally associated with } \\
\text { undisturbed conditions.' }\end{array}$ & $\begin{array}{l}\text { '(5) Human-induced eutroph- } \\
\text { ication is minimised, especially } \\
\text { adverse effects thereof, such as } \\
\text { losses in biodiversity, ecosystem } \\
\text { degradation, harmful algae } \\
\text { blooms and oxygen deficiency } \\
\text { in bottom waters.' }\end{array}$ \\
\hline $\begin{array}{l}\text { Nutrient supply, cycling rates } \\
\text { and elemental ratios are ade- } \\
\text { quate to support community } \\
\text { functioning and structure; } \\
\text { communities make efficient use } \\
\text { of these resources }\end{array}$ & \begin{tabular}{|l|} 
Nutrient seasonal \\
cycles, amounts, and \\
elemental ratios are \\
similar to those under \\
undisturbed conditions
\end{tabular} & $\begin{array}{l}\text { 'Nutrient concentrations remain } \\
\text { within the range normally } \\
\text { associated with undisturbed } \\
\text { conditions.' }\end{array}$ & Not explicitly mentioned \\
\hline $\begin{array}{l}\text { Sufficient biodiversity to fulfill } \\
\text { all the necessary bio-geochem- } \\
\text { ical roles, to support species at } \\
\text { higher trophic levels, and to } \\
\text { provide a reserve in case of loss } \\
\text { of species; keystone species } \\
\text { flourishing where essential for } \\
\text { community functioning; there is } \\
\text { a mixture of } r \text { - and } k \text {-adapted } \\
\text { species, and a mixture of repro- } \\
\text { ductive and young individuals } \\
\text { within populations }\end{array}$ & $\begin{array}{l}\text { All aspects of diversity } \\
\text { are appropriate for } \\
\text { undisturbed example } \\
\text { of ecosystem type as } \\
\text { determined by climate } \\
\text { and local (eco) hydro- } \\
\text { dynamic conditions }\end{array}$ & $\begin{array}{l}\text { 'The composition and abund- } \\
\text { ance of phytoplanktonic taxa } \\
\text { are consistent with undisturbed } \\
\text { conditions.' 'All disturbance- } \\
\text { sensitive macroalgal and angio- } \\
\text { sperm taxa associated with } \\
\text { undisturbed conditions are } \\
\text { present.' 'The level of diversity } \\
\text { and abundance of invertebrate } \\
\text { taxa is within the range } \\
\text { normally associated with } \\
\text { undisturbed conditions.' }\end{array}$ & $\begin{array}{l}\text { '(1) Biological diversity is } \\
\text { maintained. The quality and } \\
\text { occurrence of habitats and the } \\
\text { distribution and abundance of } \\
\text { species are in line with pre- } \\
\text { vailing physiographic, geo- } \\
\text { graphic and climatic conditions. } \\
\text { (2) Non-indigenous species } \\
\text { introduced by human activities } \\
\text { are at levels that do not } \\
\text { adversely alter the ecosystems.' }\end{array}$ \\
\hline $\begin{array}{l}\text { Community structure includes } \\
\text { multiple trophic levels and a } \\
\text { variety of trophic links between } \\
\text { levels; in cases where autogenic } \\
\text { or responsive successions are } \\
\text { important, then either a sub- } \\
\text { stantial proportion of the eco- } \\
\text { system is in the mature state, or } \\
\text { there are no impediments to } \\
\text { reaching such a state }\end{array}$ & $\begin{array}{l}\text { Structure is that } \\
\text { characteristic of this } \\
\text { ecosystem type under } \\
\text { undisturbed conditions }\end{array}$ & $\begin{array}{l}\text { Not explicitly dealt with by this } \\
\text { Directive }\end{array}$ & $\begin{array}{l}\text { '(4) All elements of the marine } \\
\text { food webs, to the extent that } \\
\text { they are known, occur at normal } \\
\text { abundance and diversity and } \\
\text { levels capable of ensuring the } \\
\text { long-term abundance of the } \\
\text { species and the retention of their } \\
\text { full reproductive capacity.' }\end{array}$ \\
\hline $\begin{array}{l}\text { Individual organisms are } \\
\text { healthy and reproductively fit, } \\
\text { not showing widespread pathol- } \\
\text { ogies, nor substantially contami- } \\
\text { nated with pollutants, nor ex- } \\
\text { hibiting reduced resistance to } \\
\text { disease or stress or reduced } \\
\text { ability to detoxify }\end{array}$ & \begin{tabular}{|l|} 
Body burden of \\
contaminants below \\
defined threshold; no \\
substantial differences \\
in performance com- \\
pared with individuals \\
at unpolluted station
\end{tabular} & $\begin{array}{l}\text { Pollutant concentrations 'remain } \\
\text { within the range normally asso- } \\
\text { ciated with undisturbed con- } \\
\text { ditions'. }\end{array}$ & $\begin{array}{l}\text { '(8) Concentrations of contami- } \\
\text { nants are at levels not giving } \\
\text { rise to pollution effects.' }\end{array}$ \\
\hline
\end{tabular}

to assessing ecological status. Values for physicochemical and biological quality elements are compared with those 'normally associated with that [water body] type under undisturbed conditions', i.e. with those of the type-specific reference conditions. The third column in Table 1 quotes from the Directive's specifications for high quality status, which is that of the reference condition, and which it seems logical to equate with good ecosystem health. However, finding current examples of the reference con- ditions in European coastal seas and estuaries has proven difficult (Hering et al. 2010, Borja et al. 2012).

Column 4 maps the criteria to the 'qualitative descriptors' of 'good environmental status' (GES) in the European Marine Strategy Framework Directive $(M S F D)$, which takes a functional approach to good condition, in contrast (Borja et al. 2012) to the WFD's norm-referencing.

Finally, there is another problem to be solved before using aggregation as an integrative method. It 
concerns how to combine indicators whilst (1) avoiding double-counting of primary variables and (2) recognising each indicator's importance in relation to ecosystem function. The problem is especially marked when aggregating over levels. Do community and ecosystem effects arise linearly from aggregation of organism-level and population-level effects, or can species replacement sustain ecosystem function even if some populations are damaged (for example, by pollution)? One combinatorial strategy has been to use weightings: for example, Aubry \& Elliott (2006) multiplied indicators for estuarine disturbance by weights based on expert judgements, and Borja et al. (2011) used weights based on relative importance and indicator reliability to combine ecological quality ratios, for the MSFD's qualitative descriptors of good condition, into a single integrated assessment. Another strategy is the precautionary 'one-out, all-out' principle used by the WFD (Borja \& Rodríguez 2010), where a water body is demoted from 'good' status if a single quality element is scored below 'good'. A general objection to all these procedures is that their outcomes may depend as much on decisions made about the combinatorial rules as on the actual condition of the ecosystem (Borja \& Rodríguez 2010, Caroni et al. 2013).

\section{Health as an emergent property of complex systems}

An alternative to the empirical approach is what we call systemic, because its perspective is that of health as an emergent property of the whole ecological system rather than of any of its components. According to General Systems Theory (von Bertalanffy 1968, 1972), a system is 'a set of elements standing in interrelation among themselves and with [their] environment'. The theory's principles include a subset that apply to the open, complex, hierarchical and autopoïetic systems that are exemplified by organisms and ecosystems. Living systems must be open (to their external environment) because they need a throughput of matter and energy to keep their components in a thermodynamically unlikely state (Schrödinger 1944, Boulding 1956, Lovelock \& Margulis 1976, Moss 2008). They can persist only if they can maintain their internal organization and functions against these fluxes, or are able to restore internal states after perturbation. Health, in the systemic view, is this ability: a healthy system is one that maintains its integrity and is resilient under pressure. Thus, the concept of ecosystem health is more than a metaphor carried over from human health, and it is more than the sum of properties of components. It refers to patterns of system behaviour that are common to both organisms and ecosystems, and illhealth is recognized by a breakdown of this pattern.

Systems can be characterized in 2 ways (von Bertalanffy 1968, 1972). Internal description uses state variables, and can be exemplified for biological systems by the Lotka-Volterra equations (Slobodkin 1962, Hastings 1996). In a simple case, the state variables might be the population sizes of a predator and its prey. The behaviour of even small and speciespoor ecosystems is more complex than such binary systems, and many variables may be needed to represent their internal state. Nevertheless, whether a system is simple or complex, change can be expressed 'geometrically ... by the trajectories that the state variables traverse in the state space, that is, the n-dimensional space of possible location of these variables' (von Bertalanffy 1972, p. 417). Fig. 1 de-

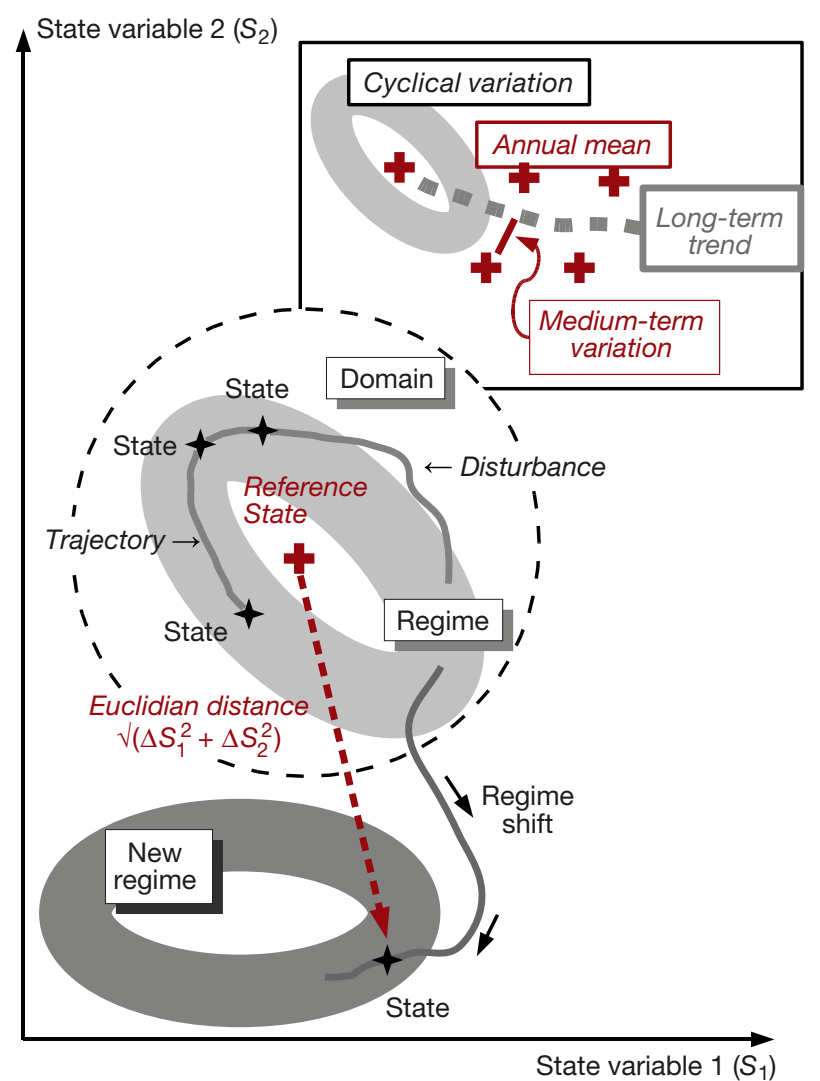

Fig. 1. Definitions relating to system state variable space, exemplified for 2 axes, but generalizable to any number of dimensions. A state is represented by a point in state space; a trajectory is a (temporal) sequence of states; a regime is a coherent bundle of trajectories, such as those arising from seasonal cycles; a domain is a region in state space. The Euclidian distance gives the (shortest) scalar distance between 2 points in a state space of any dimensionality. The inset box shows the 3 types of variability discussed in this paper 
fines the terms used in discussing such state space diagrams.

In the case of external description, the behaviour of the system is described in terms of interactions with what is outside the system, often by specifying the relationship between inputs to the system and the resulting outputs. Fig. 2 combines a systemic view of an ecosystem with the Driver-Pressure-StateImpact-Response (DPSIR) paradigm of Luiten (1999) as updated by Atkins et al. (2011). Anthropogenic disturbance to trans-boundary fluxes constitutes a pressure, resulting in changes in the (internal) state of the system with consequent impacts on society. Resilience is the system property that determines the response of state to a pressure change; it is an emergent property because it cannot be localized in any particular component of the system.

Following a review of system-based definitions of health (Table S4 in Supplement 3), Costanza (1992) proposed that ecosystem health was best seen as a comprehensive, multiscale, dynamic, hierarchical measure of system resilience, organization, and vigour, [concepts that] are embodied in the term 'sustainability' which implies the system's ability to maintain its structure (organization) and function (vigour) over time in the face of external stress (resilience).
All 3 components are necessary (Mageau et al. 1995): (1) a system lacking in vigour would tend towards abiotic thermodynamic equilibrium; (2) systems with excess vigour but 'little or no organization, such as nutrient enriched lakes, ..., or early successional ecosystems dominated ... by ' $r$ ' selected species' (p. 204) tend towards excessive blooms; and, (3) 'certain highly managed systems, such as agriculture, aquaculture, and plantations' (p. 204), lack resilience and require continuous human intervention for their maintenance. Costanza \& Mageau (1999) thought that organization might be quantified through the analysis of trophic networks (e.g. Ulanowicz \& Kay 1991, Christensen \& Pauly 1992) and vigour quantified by measurements of 'ecosystem metabolism', including its primary production.

Resilience is presently seen as the key component of system health. Holling (1973) defined it as 'a measure of the ability of [eco]systems to absorb changes of state variables, driving variables, and parameters' (p. 17) without ceasing to exist. Folke et al. (2004) saw resilience as 'the capacity of a system to absorb disturbance and reorganize while undergoing change so as to maintain essentially the same functions, structure, identity and feedbacks' (p. 558). Loss of resilience is now seen as leading to regime shift: a

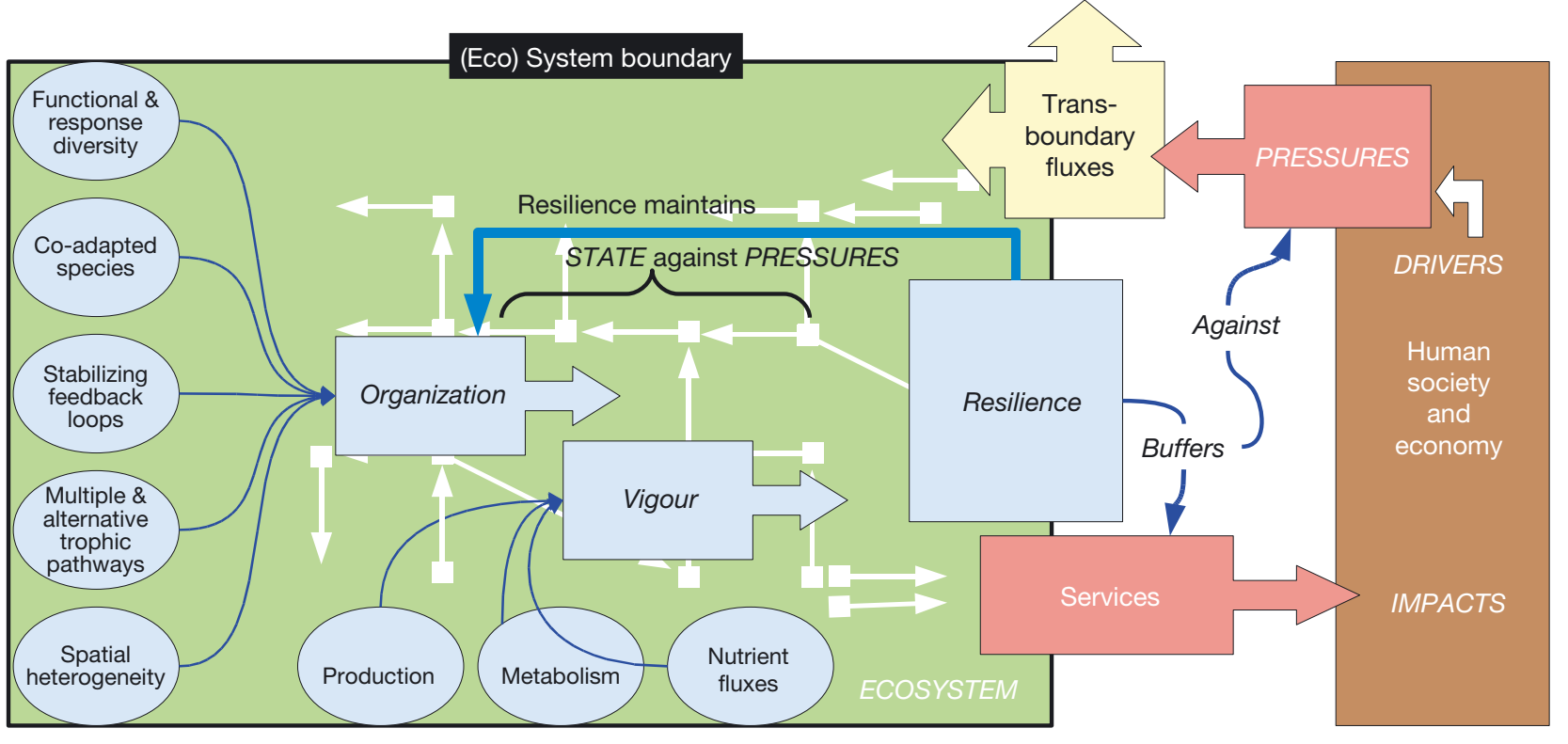

Fig. 2. A systems conceptualization of ecosystem health. Ecosystem components (biota, their non-living environment, and trophic and biogeochemical fluxes) are suggested by the white network. Overlying this are the high-level 'internal descriptors' of system state: organization and vigour. These are responsible for the external property of resilience, which buffers ecosystem state and services against externally imposed (anthropogenic) pressures and other boundary fluxes, thus maintaining system integrity. Health describes the ability to maintain systems integrity, and it and resilience are emergent properties of the system; they cannot be localized into any particular component. At the left are listed the attributes of organization that are thought to contribute to resilience. Components of vigour are shown at the base of the ecosystem box. To the right is shown the matching human system, which together with the ecosystem, makes up a social-ecological system. Only endogenous pressures-those generated within this system-are shown 
change to a new internal organization, rather than extinction. Holling (1973) visualized continued existence as requiring trajectories in state space to remain within a basin of attraction, and distinguished resilience from 'stability'-'the ability of a system to return to equilibrium after a temporary disturbance' (p. 17). Much subsequent literature, however, has equated 'resilience' with Holling's stability and the ability to recover after perturbation. This included Elliott et al. (2007) and Tett et al. (2007). However, it now seems best to see resilience as having several components, one of which is recovery to 'equilibrium', bearing in mind that the restored equilibrium may be dynamic or correspond to a complex attractor in state space (Gowen et al. 2012). Other components of resilience (Walker et al. 2004) are resistance to pressure, and latitude: the greatest amount that a system can change before losing its ability to regain (or remain in) its original regime, and corresponding to the size of Holling's 'basin of attraction'.

Like Scheffer et al. (2001), Folke et al. (2004) argued that anthropogenic disturbance to ecosystems reduces resilience and increases the chances of regime shift. This leads to the metaphor of the 'cliff' in pressure-state diagrams (Fig. 3) (Elliott et al. 2007, Tett et al. 2007, van de Koppel et al. 2008). The paradigm in such diagrams is that natural ecosystems are resilient, and so resistant to anthropogenic pressures. Beyond a certain level of pressure, however, there is

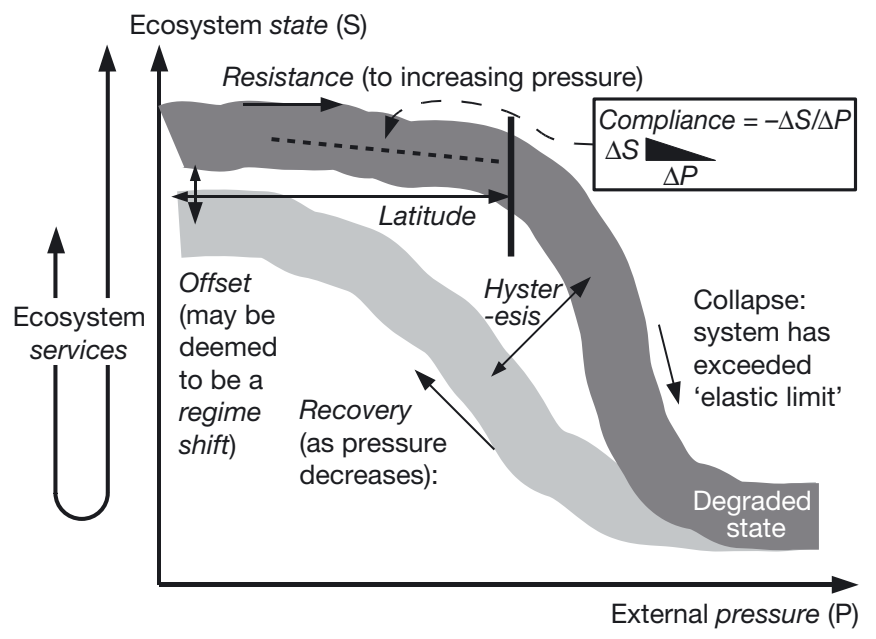

Fig. 3. The cliff metaphor for change in ecosystem state (modified from Elliott et al. 2007 and Tett et al. 2007) used to illustrate resilience components (Walker et al. 2004) in terms of the effects of external pressure $(P)$ on ecosystem condition or state $(S)$. Latitude is shown as analogous to the 'elastic limit' of a mechanical system. Beyond this limit, the system deformation no longer changes linearly with pressure. Compliance is the ratio of state change to pressure change and thus is the inverse of resistance a danger of ecosystem collapse, from which it might be difficult to recover speedily (or at all) to the original conditions. An alternative metaphor (Fig. 4) is that of a stability landscape, in which a ball (representing system state) rolls to the lowest point in the valley, but can be displaced into other valleys either by change in the landscape or by increased movement of the ball (Scheffer et al. 2001, Walker et al. 2004). Duarte et al. (2009) pointed to the problem of 'shifting baselines' encountered when attempting to return an ecosystem to a prior state, such as that existing before eutrophication. They illustrated the problem with plots of state against pressure (corresponding to Fig. 3), but it could also be seen in terms of the changes in the topography of the landscape in Fig. 4. Finally, Scheffer et al. (2009) suggested that systems (such as ecosystems, but also economies) showed an increase in variability as they approached 'critical transitions' between regimes.

The idea of panarchy (Gunderson \& Holling 2002, Holling 2004) is that on any particular spatial scale, systems naturally go through periods of collapse and recovery. During recovery, a system can adapt to changed circumstances, because post-collapse conditions can select for different species (in an ecosystem) or different institutions (in a society). The concept of panarchy also includes the interactions of

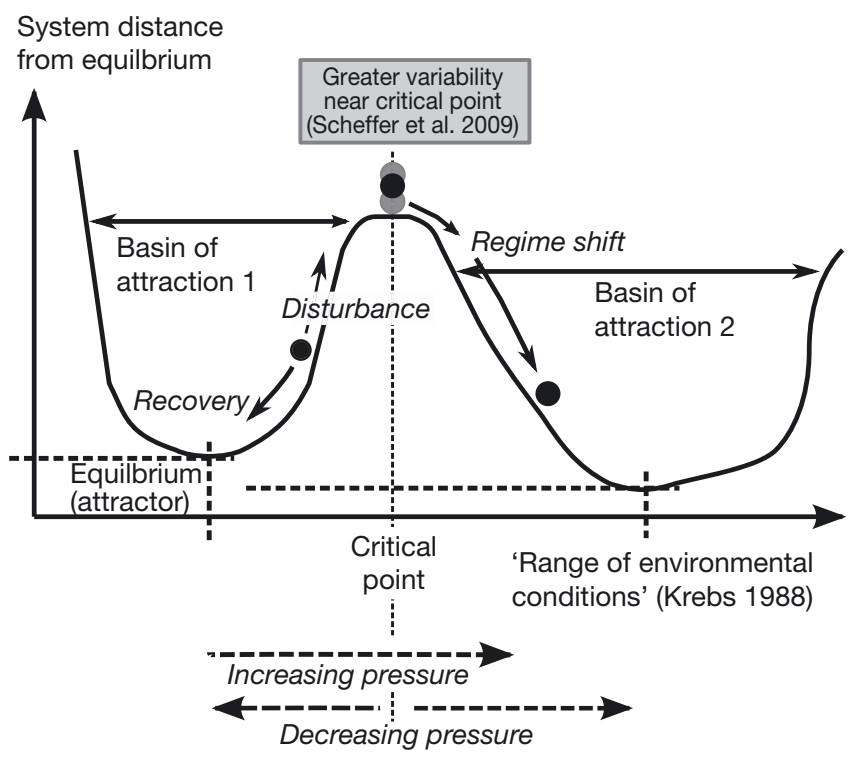

Fig. 4. The landscape metaphor for stability and regime shift (Holling 1973). The ball, representing ecosystem state, moves between valleys denoting different regimes, following disturbance to the ball (Krebs 1988) or changes in the landscape (Scheffer et al. 2001). In the metaphor, stabilizing effects are likened to gravity. In mathematical terms, stability is the result of the system's tendency to move towards an attractor state, shown at the bottom of each basin 
growth-collapse-recovery cycles across spatial scales or up and down hierarchies within the main system. Thus, heterogeneity within an ecosystem may contribute to vigour and resilience.

Although widely applied, a systemic approach to ecosystem health is currently less a refutable theory and more a point of view. Its cliff and landscape metaphors provide explanations that are useful in the public domain. The challenge, however, is to find ways to quantify ecosystem organization and vigour, and to understand how these quantifications relate to ecosystem resilience so that useful predictions of future ecosystem condition can be made from observations of present state and pressures.

\section{Organization and biodiversity}

Costanza \& Mageau (1999) explained 'high organization' as 'an efficient diversity of components and exchange pathways', and proposed its quantification through network analysis (Ulanowicz 1979, 2009). Despite some applications of the network approach (Christensen 1995, Christian et al. 2010), the difficulty in obtaining adequate data about exchanges has meant that most attempts to understand ecosystem function in terms of structure have continued to focus on the diversity of components rather than on the diversity of pathways in trophic or biogeochemical networks.

Biodiversity has a range of meanings. The 1992 international Convention for Biological Diversity (CBD) defined it as 'the variability among living organisms from all sources ... within species, between species, and of ecosystems' (Millennium Ecosystem Assessment 2005). Here, we define biodiversity as the phenotypic variability amongst organisms within an ecosystem, and the genetic basis of that variability. In most eukaryotes, that genetic basis is largely organized into reproductively isolated species, and it is at the level of species that biological diversity has mainly been studied. This focus derives from the standard paradigm of evolutionary ecology, which is that a species is a self-contained gene pool competing with other gene pools for territory in niche hyperspace, and thus fitness to survive in the physical world (Hutchinson 1957, 1965).

This paradigm has led some to propose equilibrium models of species-abundance distributions based on niche apportionment theory (MacArthur 1957, Tokeshi 1993). However, others view species diversity as a non-equilibrium phenomenon: the result of high physical disturbance, or chaotic internal interactions, allowing multiple species to occupy 1 realized niche, and thus explaining (Scheffer et al. 2003) 'the paradox of the plankton' in aquatic ecosystems (Hutchinson 1961). Is high species diversity, then, more a symptom of instability than a cause of stability? Or can a diversity of non-equilibrium states contribute to ecosystem resilience under fluctuating conditions?

Many (perhaps too many; Green \& Chapman 2011) indices of species diversity have been proposed (Washington 1984, Magurran 2004, Gray \& Elliott 2009). The simplest are (1) empirical, such as the number of species scaled to the number of individuals in a sample. Others derive from: (2) models for species-abundance relationships (McGill et al. 2007); (3) the information content of a community, or a representative sample, containing a set of taxa of quantifiable abundance; or (4) the probabilities of different sorts of inter-organism encounter (Hurlbert 1971). Type (3), exemplified by the index of Shannon (1948), applies to any set of objects, and essentially treats variety in a system as if it were a message containing information about the system. Hurlbert (1971) argued in favour of (4) on the grounds that, whereas the message might be meaningful to ecologists, what was important to organisms was whether the next encounter would be with a mate, food item, or predator.

Contrary to Hurlbert's argument, a diversity statistic based on species abundances or information theory can aggregate much of the fine grain of organism-level interaction, and might be deemed useful if it could be shown to correlate with, for example, resilience. Disappointingly, most meta-studies fail to find relationships between standard species diversity measures and ecosystem functions that are consistent over a variety of ecosystems (e.g. Hooper et al. 2005). Ives \& Carpenter (2007) concluded that 'diversity-stability relationships' were complex, and that anthropogenic changes often affect stability and diversity simultaneously. Hooper et al. (2005) (Table S5 in Supplement 3) cited mostly positive effects of biodiversity on terrestrial ecosystem services, on 'production and nutrient retention' (which we equate with vigour), and on stability. They therefore argued that the diversity of functional traits was more important than the diversity of species. Likewise, Bengtsson (1998) argued that, for the management and development of sustainable ecosystems, it is probably more important to understand the linkages between key species or functional groups and ecosystem function, rather than focusing on species diversity.

Folke et al. (2004) distinguished functional-group diversity and functional-response diversity. The former refers to diversity between sets of species (not 
necessarily taxonomically related) that carry out similar roles within an ecosystem, and hence quantifies the variety of ecosystem processes. Loss of a functional group results in a major change in ecosystem functioning. Functional-response diversity refers to variety in the 'response to environmental change among species that contribute to the same ecosystem function' (i.e. within a functional group; Folke et al. 2004 , p. 570), and provides 'a degree of ecological insurance against ecological uncertainty' (Hughes et al. 2005, p. 383). However, if all species within a functional group respond similarly to pressures, then higher biodiversity will not afford additional protection. Estuaries exemplify naturally species-poor systems that are fully functioning and resilient (Elliott \& Whitfield 2011). Osmotic stress excludes many species, but the few that can flourish here are those that are tolerant of disturbance, and it appears that they can supply all necessary ecosystem functions. Adaption to pressure might take place within species' populations rather than by changes in the species assemblage as might occur in more speciesdiverse systems.

We conclude that functional-group diversity is the key component of ecosystem structure, that it is qualitative as much as quantitative, and that it can be thought of as a set of dimensions (i.e. axes in state space) relevant to a particular biome. Supplement 4 exemplifies this for soft-bottom communities in coastal waters.

\section{Ecosystem change and regime shift}

Marine ecosystem services provide benefits to human communities, valued at about 20 trillion US\$ per year in 1994 (Costanza et al. 1997). A powerful argument for understanding, evaluating and managing marine ecosystem health is the link from health and resilience to ecosystem function and services. Ecosystems and their services change naturally, but the rate of change seems to have increased as a result of human activity in the 'Anthropocene' (Crutzen \& Stoermer 2000, Crossland et al. 2005). Some alterations within ecosystems impact directly on services, but the cliff metaphor (Fig. 3) suggests the additional risk that changes can compound-leading to a 'tipping point' beyond which there is a partial collapse of existing system organization and a change to a new configuration. The new condition may provide fewer, or different, services; and the transition may prove difficult for social groups or economies that depend on particular services.
Such transformations of ecosystems are increasingly referred to as regime shifts, defined as 'relatively sudden changes between contrasting, persistent states of a system' (deYoung et al. 2008) or 'sudden changes in ecosystem structure that can be detected across several ecosystem components' (Spencer et al. 2011). They are said (Scheffer et al. 2001) to have been observed in major terrestrial and marine ecosystems. The latter include: coral reefs (Nyström et al. 2000); the north Pacific Ocean (Hare \& Mantua 2000); Ringkøbing Fjord (Petersen et al. 2008); and the North Sea (Reid et al. 2001, Beaugrand 2004, Weijerman et al. 2005, Spencer et al. 2011). In the northwestern Atlantic Ocean, from the Gulf of Maine to the Grand Banks of Newfoundland, there have been major changes in fisheries and ecosystems (Rose 2003, Buchsbaum et al. 2005, Bundy \& Fanning 2005), with consequences that include reduced diversity of harvest and a simplified food web structure. These 'may increase risks of ecological and economic disruptions' (Steneck et al. 2011).

What are claimed as steps might be artefacts of the numerical methods used in analysis (Spencer et al. 2011). Nevertheless, large changes do occur, and what seems crucial from a human perspective is that the ecosystem has reached a new condition, qualitatively different from that in which it was originally found; that the new state is persistent; and that it provides different services.

As Scheffer et al. (2001) point out, 'the notion that ecosystems may switch abruptly to an alternative state emerged from theoretical models'. Solutions to dynamic models with 1 or 2 equations show a range of responses of system state variables to linear increases in forcing (May 1977, Collie et al. 2004). These responses may be 'smooth' (i.e. linearly proportional), 'abrupt' (i.e. showing a runaway response) or 'discontinuous' (in which the system skips to a non-adjacent state), depending on parameter values in the equations. Boundary exchange can suppress such discontinuities (van de Koppel et al. 2008). These models provide insights into ecological dynamics, but may be too simple to quantify real ecosystem behaviour. Most theoretical thinking about regime shift has used conceptual rather than numerical or analytical models, such as the cliff and landscape metaphors in Figs. 3 \& 4.

Under both landscape and cliff metaphors, a system's approach to the point at which regime shift occurs is associated with a breakdown of resilience. In the most general, systemic terms, the breakdown is a temporary loss of negative (stabilizing) feedback loops, so that for a time the system becomes domi- 
nated by positive (disruptive) feedback before settling into a new basin of attraction (either in a metaphorical landscape or in state space). As considered in the preceding subsection, more concrete explanations might involve loss of functional and response diversities, erosion of trophic networks or disturbances to ecosystem metabolism, associated with the symptoms of ecosystem pathology (Tables S2 \& S3 in Supplement 2). A purely empirical explanation would centre on the loss of key stabilizing components; for example, explaining the decline of Alaskan kelp forests by increased echinoderm grazing following a decline in sea-otters (Estes \& Duggins 1995), which was perhaps due to increased predation by killer whales deprived of their former prey, the great whales (Estes et al. 2004).

Substantial changes have already occurred in coastal ecosystems as a result of human removal of most large marine vertebrates, including whales, dugongs, turtles and larger fish (Jackson et al. 2001, Estes et al. 2004, Thurstan \& Roberts 2010). The consequences include greater risk of eutrophication because of 'microbialization of the global coastal ocean' (Jackson et al. 2001). It is not clear that such changes would fully reverse were fisheries and other pressure to be relaxed and coastal environments restored (Duarte et al. 2009), and in any case, such relaxation and restoration might be difficult to achieve. Nevertheless, the depleted systems (although changed in organization) might retain sufficient functional diversity and resilience to continue providing some services despite external pressures.

The hypothesis that altered ecosystems might be healthy systems is of considerable practical importance. Although arguably incompatible with laws, such as the WFD, which equate good status solely with that of 'reference conditions' (see 'Ecosystem health as an aggregate property', above), the hypothesis is consistent with the requirements of other laws, such as the MSFD (Borja et al. 2012), that define 'good environmental status' as that of seas that are functioning well and providing for sustainable use.

\section{THEORY OF ECOSYSTEM HEALTH}

\section{Definition and components of ecosystem health}

As shown above, there are diverse opinions about the nature of ecosystems and what is to be understood by calling them healthy. Nevertheless, there is a need for guidance on how to protect marine ecosystems. One strategy is to seek consensus amongst a group of experts (e.g. Foley et al. 2010). Such a group (the authors of this article) met in Lowestoft, UK, at a series of workshops in 2010, tasked with: (1) developing a theory of ecosystem health, and (2) suggesting how this theory might be used for evaluating the holistic state of marine ecosystems in the context of European requirements to maintain good ecological status (WFD) and good environmental status (MSFD).

Participants agreed on a definition of health that took account of both the empirical and the systemic views:

Ecosystem health depends on: the physiological health of the constituent organisms; the characteristic properties and interactions of the species present; and the emergent properties of the system comprising the biota and their environment. Healthy ecosystems can sustain services to humans. They are vigorous, resilient to externally imposed pressures, and able to maintain themselves without human management. They contain organisms and populations that are free of stress-induced pathologies, and biodiversity that includes (1) a functional diversity enabling all biogeochemical and trophic functions appropriate to the ecohydrodynamic conditions, and (2) a diversity of responses to external pressures. All expected trophic levels are present and well interconnected, and there is good spatial connectivity amongst subsystems.

Any assessment of ecosystem health in relation to this definition must be made on appropriate spatial and temporal scales, and must take into account the local ecohydrodynamic conditions and the degree of openness of the system's boundaries.

To the original 3 health components of vigour, organization and resilience (Mageau et al. 1995, Costanza \& Mageau 1999), workshop participants added hierarchy (including spatial granularity) and trajectory, to take account of ecological variability in space and time (Table 2). We could not identify simple indicators of ecosystem health. Instead, we propose the use of trajectories in state space to assess change in ecosystem condition. The definition of health, and the proposal to use trajectories, constitutes a framework for understanding marine ecosystem health which we hope will influence programmes for monitoring coastal waters and managing pressures thereon.

\section{Extent and granularity of an ecosystem}

The first task in applying the framework is to define an ecosystem's extent and describe its boundaries: where they are, what crosses them, and what is included within them. The boundaries may be fixed 
Table 2. The proposed 5 components of ecosystem health

\begin{tabular}{|c|c|c|}
\hline Component & Definition & Explanation \\
\hline $\begin{array}{l}\text { Structure or } \\
\text { organization }\end{array}$ & \begin{tabular}{l|} 
The types and \\
arrangements or \\
interconnections of \\
the components of a \\
system
\end{tabular} & $\begin{array}{l}\text { If the system is thought of as a net, then this component comprises both the nodes and the } \\
\text { links-the components and their connections; however, the nodes correspond to } \\
\text { functional groups rather than species, and thus structure is not related to biodiversity as } \\
\text { measured by number of species or related indices, but to functional diversity and (trophic) } \\
\text { connectance }\end{array}$ \\
\hline Vigour & $\begin{array}{l}\text { The ability of a } \\
\text { system to maintain } \\
\text { or renew its } \\
\text { organization, } \\
\text { drawing on } \\
\text { production }\end{array}$ & $\begin{array}{l}\text { Vigour concerns the functioning of the network-if that is seen as a set of pipes, then } \\
\text { vigour concerns the fluxes through the pipes, and so would include primary production, } \\
\text { nutrient cycling, and balance terms such as net production, or ratios such as that of } \\
\text { production to respiration or allochthonous to autochthonous production; it might also } \\
\text { include reproductive vigour and successional vigour, the potential for the biotic } \\
\text { community to recolonize a region that has suffered disturbance }\end{array}$ \\
\hline Resilience & $\begin{array}{l}\text { The capacity of } \\
\text { a system to maintain } \\
\text { its integrity under } \\
\text { pressure }\end{array}$ & $\begin{array}{l}\text { Resilience emerges (in the systemic view) from organization and vigour, and, empirically, } \\
\text { may depend in part on key species and on functional response diversity; it is an } \\
\text { ecosystem's capability to maintain its functions and structure under external pressure, } \\
\text { either by resistance to the pressure, recovery from its effects, or adapting to it; when this } \\
\text { capability is exceeded then there is a regime shift }\end{array}$ \\
\hline $\begin{array}{l}\text { Hierarchy } \\
\text { and } \\
\text { granularity }\end{array}$ & $\begin{array}{l}\text { The distribution and } \\
\text { interconnection of } \\
\text { sub-systems and } \\
\text { subregions within } \\
\text { the ecosystem }\end{array}$ & $\begin{array}{l}\text { Hierarchy includes both (1) the ecological equivalent of 'subsidiarity', the existence of } \\
\text { subsystems that can to some extent function independently (e.g. pelagos, benthos), and } \\
\text { (2) granularity, the existence of spatially distinct subregions that can re-seed adjacent } \\
\text { subregions following disturbance; spatial connectivity refers to the links between these } \\
\text { subregions; all these aspects (sometimes linked under the title of panarchy) might } \\
\text { contribute to resilience }\end{array}$ \\
\hline Trajectory & $\begin{array}{l}\text { A sequence of } \\
\text { system states plotted } \\
\text { in state space }\end{array}$ & $\begin{array}{l}\text { Refers to change in the internal description of an ecosystem: the way in which system } \\
\text { state, including structure and vigour, changes with time, resolved on an appropriate } \\
\text { scale; trajectory, plotted in state variable space, and related to pressures, is diagnostic in } \\
\text { that it allows resilience to be estimated, and could be prognostic (of decreasing or } \\
\text { recovering health) if there was a theory or model that allows a domain of good health } \\
\text { (high resilience) to be located in a state space diagram }\end{array}$ \\
\hline
\end{tabular}

by natural features, but are typically drawn by human custom or legislation. European examples include the 'waterbodies' of the WFD and the large marine 'subregions' of the MSFD (Borja et al. 2010).

The second task concerns how to deal with hierarchy: the existence of functionally distinct subsystems (such as pelagos and benthos) and spatial patchiness. Granularity can arise in the benthos from a patchwork of sediment types (Künitzer et al. 1992), or in the plankton from differing spatial and temporal patterns of mixing and stratification (Pingree \& Griffiths 1978, Tett et al. 2007). It can also result from internal dynamics, such as the local settlement, growth and mortality of a cohort that temporarily dominates a region of benthos (Pearson \& Barnett 1987), or from gradients of anthropogenic pressure, as with increasing distance from a fish farm (Brown et al. 1987, Nickell et al. 2003) or an urbanized coast (Garmendia et al. 2011). As discussed, resilience may in part derive from spatial connectivity and the possibility of one sub-region reseeding another after local collapse. Connectivity can be physical, for example when larvae are transported by water movements, or biological, for example, migration to exploit seasonally varying food supply. Life cycle closure theory (Sinclair 1987, Sinclair \& Iles 1989) suggests that species' populations adapt their migratory and repro- ductive behaviour to prevailing circulation patterns (Peterson 1998).

A variety of methods are available for observing spatial variability in marine ecosystems (Table S7 in Supplement 5). Such variation, if analysed in terms of ecosystem health, can be related to gradients of pressure and thus used to understand and manage the pressures that disturb health (COM 2010). In addition, we anticipate that the use of these methods will lead to a better understanding of the role of spatial variation in holistic ecosystem function. For now, we propose to smooth out such variability by spatially aggregating or averaging, and to deal with hierarchy by seeing it as part of system organization and hence by a suitable choice of system state variables.

\section{Organization and vigour}

The conclusions of the review were that key aspects of ecosystem organization are (1) spatial heterogeneity and connectivity, (2) functional diversity and response diversity, (3) trophic connectance, and (4) the existence of co-adapted species and stabilizing feedbacks. Vigour is the ability to maintain or renew organization (Costanza 1992). At the level of the system, it concerns biogeochemical fluxes, espe- 
cially of compounds of carbon, nitrogen and phosphorus, and associated biochemical energy. At the level of species, it concerns population maintenance, requiring not only reproductive success but in some cases also adequate spatial connectivity. At the level of the community are successional processes, which in marine systems may include seasonal plankton cycles (Margalef 1978) or benthic recovery from disturbance (Pearson \& Rosenberg 1976), and which are illustrated as the doughnut-shaped bundles of trajectories in Fig. 1. Finally, there is the idea of balance to be considered: not a static balance in which every part of the food web is in harmony, but a dynamic and panarchic balance in which populations fluctuate and are replaced, allowing ecosystems to adapt to pressures.

Understanding these issues, and their contribution to ecosystem resilience, is a crucial challenge for those studying community ecology. Some progress has been made since Holling's (1973) pessimistic conclusion that estimating resilience, by measuring the extent of the 'domain of attraction' in state space, will 'require an immense amount of knowledge of a system and it is unlikely that we will often have all that is necessary' (p. 20). Salihoglu et al. (2013) report progress in coupling community ecology with observations and modelling of biogeochemical cycles in large marine ecosystems. Nevertheless, it is not yet possible to state, in quantitative terms, a functional relationship between organization, vigour and resilience.

\section{Trajectories in state space}

Given the lack of sufficient theory-based understanding of the holistic functioning of ecosystems, we opted for a more pragmatic approach. This involves the analysis of trajectories in state space, and is compatible with both empirical and systemic views.

Movement in state space has several components (Fig. 1): repeating or semi-cyclical variation, mediumterm variability, and long-term movement relative to a reference condition. State space plots do not include a time-axis, but variation such as that associated with seasonal cycles of plankton will show as loops, which might be seen as part of ecosystem organization (Tett et al. 2007). Similar semi-closed trajectories might result from succession (and return to climax) after disturbance. Although the phenology of seasonal change is itself important (Racault et al. 2012), the topic of cyclical variation is outside the scope of the present review, and we smooth it by plotting annual mean states. 'Medium-term' variabil- ity is the difference between successive means or the deviations of these means from a long-term trend.

Estimation of such a trend requires a reference point from which (or to which) distance can be calculated. For present purposes this reference point is arbitrary, and need not be identified with formerly pristine conditions or with any desired ecosystem state.

\section{Scalar distance in state space}

Simple mathematical systems and controlled laboratory experiments can fully describe system state by 1 or 2 variables, and can control all except 1 dimension of pressure; but this is unlikely to be true of natural marine ecosystems and the multiple pressures to which they are exposed. Yet it aids explanation and understanding if, as in Fig. 3, multidimensional changes in ecosystem state and in pressure can be shown as single variables. Such a simplification can be made in several ways: (1) given the identification of a reference domain in state space, observations might be characterized as either within or outside this domain, as in the 'Phytoplankton Community Index' (Tett et al. 2008); (2) by using a principal axis obtained by multivariate (statistical) analysis (Muxika et al. 2007, Kenny et al. 2009); or (3) calculate the unidimensional Euclidian distance between points in state space (see Fig. 1, Supplement 6). It is this latter option that we adopt in the next section, to estimate distance travelled from a reference condition.

A state space approach, with orthogonal axes, implies that all state variables are of equal worth in quantifying state, and thus potentially avoids one of the difficulties in aggregating ecosystem status components. Furthermore, because the axes are orthogonal, it is unnecessary to require variables to be measured in the same units. However, it is desirable to standardize the axes in some way, for convenience in viewing state space diagrams as well as for combining movements along the axes into a scalar quantity. Logarithmic transformation of planktonic data is often adopted in the interests of normalizing variability (Barnes 1952) and has the additional advantage of approximating relative change (since $\ln [x] \approx \Delta X / X$ for small changes) and homogenizing units prior to combination in Euclidian distance. Multivariate analyses typically go on to divide variables by their standard deviations, but this may be a step too far when assessing movement in state space: it may be desirable to give more weight to variables that are relatively more changeable. 


\section{Pressure-state model based on an elasticity metaphor}

It is an axiom of the DPSIR (and similar) frameworks that a change in pressure causes a change in ecosystem state. According to the systemic view of ecosystem health, the extent of the state change for a given pressure change is a function of the resistance component of the system's resilience (Walker et al. 2004). Our proposal is to relate change in ecosystem state to change in pressure on the analogy of Hooke's Law of elasticity in mechanical systems. It is assumed that values of the state and pressure variables have been averaged over appropriate spatial and temporal scales so as to remove effects of spatial heterogeneity and cyclical variation. We define ecosystem compliance (Fig. 3) as the ratio of state change to pressure change, i.e. as the analogue of the coefficient of elasticity in Hooke's Law and the reciprocal of ecological resistance. An ecosystem with high resistance will comply only weakly with pressure increases, so long as the system remains (in the elasticity analogue) within its elastic limit, within a valley in the landscape metaphor (Fig. 4), or before it reaches the cliff in Fig. 3.

Scheffer et al. (2009, 2012; see also Lenton 2013) suggested that increased variability was a sign of decreasing system resilience, and hence could provide an early warning of regime shift. Such variability can be demonstrated numerically in solutions of simple models (Collie et al. 2004). Ecosystems are more complex than these models, but the mechanistic explanation can be used as an analogy: a system on the cusp of a regime shift can be thought of as being pulled in several directions by 'attractors' for the old and new regimes. If it is also subject to other dynamic fluctuations, it may experience large fluctuations in condition before settling down into a new regime. The elasticity metaphor for resilience also leads to the prediction (Supplement 6) that mediumterm variability will increase as resilience decreases, without any corresponding increase in pressure variability. Thus, we propose to use medium-term variability as a proxy for (inverse) resilience, without further considering pressure-state relationships.

\section{Data requirements}

The proposal to track the state of an ecosystem by plotting its condition in successive periods as a sequence of points in state space does not strongly constrain the choice of state variables. Given selfstandardization to ensure that axes are of equal worth, there is not even a requirement for consistency in units. Thus, it should be possible to use variables that reference system organization alongside those that refer to vigour. It is, however, crucial that the selected variables should comprise an overall view of an ecosystem, whilst avoiding redundancy.

Another requirement is for time-series that are long enough for trends to be distinguished from the medium-term variability used as a proxy for resilience in the type of analysis that we propose. The next section contains an example, not intended to be definitive, of a state space analysis of a few timeseries of adequate length from a large marine waterbody: the North Sea.

\section{EXAMPLE OF THE STATE SPACE APPROACH}

\section{The North Sea ecosystem}

The North Sea is a large continental shelf sea which exchanges with the northeast Atlantic Ocean across its northern margin and, indirectly, through the Strait of Dover at its southern extremity. It receives significant freshwater inputs from the Baltic Sea via the Kattegat in the east, and from major rivers such as the Rhine along its southeastern flank (Rodhe 1998). Its ecosystems are subject to pressure from fisheries, nutrient enrichment, seabed disturbance and toxic pollutants (Ducrotoy \& Elliott 2008).

The North Sea can be viewed as a semi-enclosed box with a mean flushing time of about $1 \mathrm{yr}$, and thus as a single ecosystem over which trophic fluxes can be averaged (Rodhe et al. 2006). Alternatively, the sea can be sub-divided into ecohydrodynamically distinct pelagic regions (Tett et al. 1993, Rodhe et al. 2006), zones of benthic associations related to sediment type (Künitzer et al. 1992), or areas shown to be similar by empirical statistical analysis (Kenny et al. 2009).

To avoid difficulties in aggregating data from different ecohydrodynamic regions, we focus here on the northwestern part of the North Sea (Fig. 5), a region defined by the Continuous Plankton Recorder Survey as Standard Areas B2 and C2 (Reid et al. 2003). Offshore waters of this region range in depth from $\sim 60$ to $120 \mathrm{~m}$ deep and are thermally stratified during late spring, summer and early autumn.

\section{Choice of state variables}

Three variables were chosen to represent different parts of the food web. They were the rearing success 
of black-legged kittiwakes Rissa tridactyla, the abundance of the copepod genus Calanus, and simulated net annual water column primary production. In the terms introduced in the section 'Health as an emergent property of complex systems' above, primary production and kittiwake rearing success might be taken as indicators of vigour, and the 3 variables collectively indicate the organization of the food web. The variables are not homogenous either in their units, or as functional entities. Nevertheless, they serve to demonstrate the state space method and to show that it does not impose strong constraints on the data that may be used.

Data for kittiwake rearing success, defined as chicks fledged pair ${ }^{-1} \mathrm{yr}^{-1}$, were taken from several sources. Annual averages for all Scottish nesting sites observed by the UK Seabird Monitoring Programme (SMP) between 1986 and 2008 were taken from JNCC (2011). Most of these sites ( $>75 \%$ of those in Scotland) are on the Orkney and Shetland Islands and the east coast of Scotland (Mitchell et al. 2004). Five-year running means for 1956 through 1980 (Coulson \& Thomas 1985) from a single kittiwake colony in North Shields (northeast England, at $55.0^{\circ} \mathrm{N}$, on the southern boundary of the study region) were used to extend the series. Turner (2010) reports rearing success for the same colony in 2000.

The rearing success of kittiwakes is presumed to depend on the abundance of juvenile herring (Coulson \& Thomas 1985) or sand-eels (Wanless et al. 2007) near the surface of the sea. Feeding areas were assumed to be mainly in the offshore North Sea.

Calanus spp. numbers were taken from Continuous Plankton Recorder $(C P R)$ surveys (Warner \& Hays 1994). These may underestimate real abundance (Dippner \& Krause 2013), but what we require is relative consistency over the time-series. Annual means were calculated from counts on samples from CPR regions B2 and C2. Sample values (copepods per tow unit, i.e. in about $3 \mathrm{~m}^{3}$ of water) were interpolated for each month onto a uniform grid of $1^{\circ}$ longitude by $0.5^{\circ}$ latitude (Vezzulli \& Reid 2003). We combined the abundances of Calanus finmarchicus and C. helgolandicus, viewing the genus as an example of a functional type, with the species providing functional response diversity.

Net annual water column primary production (g C $\mathrm{m}^{-2}$ ) was estimated from a North Sea hindcast with European Regional Seas Ecosystem Model (ERSEM; Baretta et al. 1995, Ruardij \& Van Raaphorst 1995) linked (Lenhart et al. 2010, van Leeuwen et al. 2013) to the General Estuarine Transport Model (GETM; Burchard \& Bolding 2002). Climatological boundary

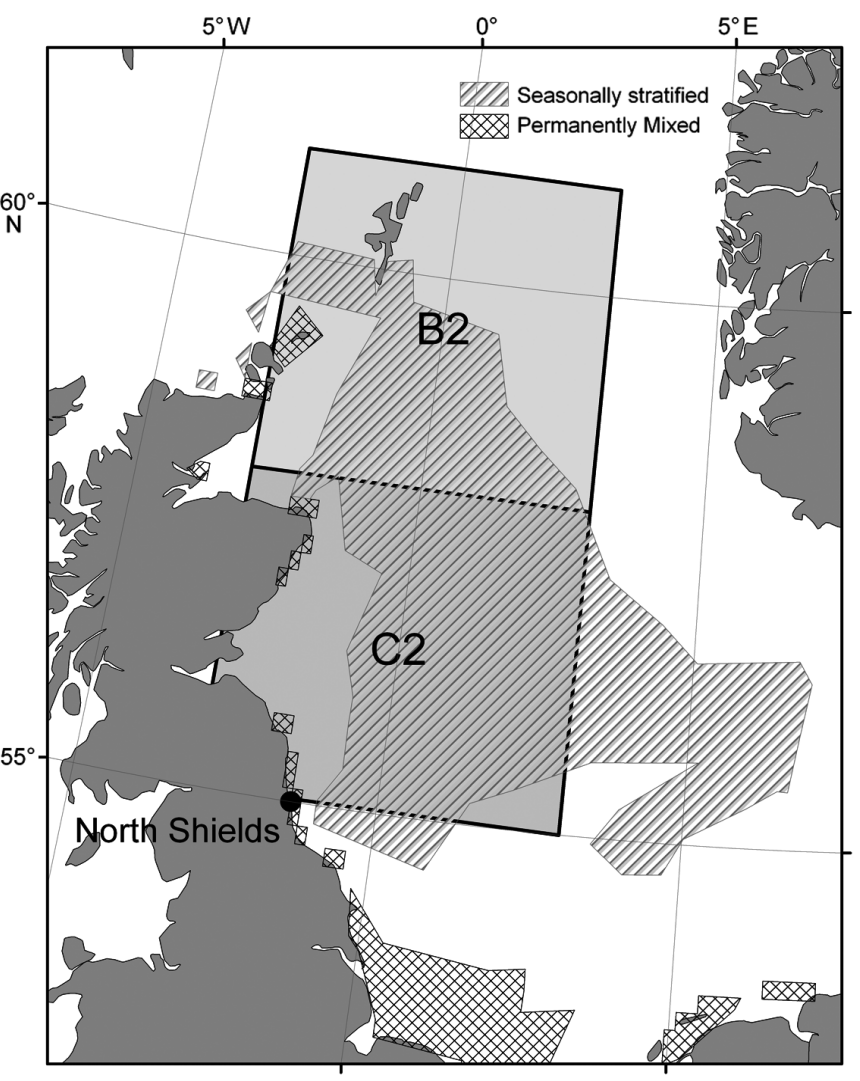

Fig. 5. Part of the North Sea, showing the Continuous Plankton Recorder $(C P R)$ regions B2 and $\mathrm{C} 2$ used for copepod data and for which primary production was calculated from a hindcast simulation with the General Estuarine TransportEuropean Regional Seas Ecosystem (GETM-ERSEM) model. Results from the GETM physical model (S. van Leeuwen unpubl. data) were also used to define the ecohydrodynamic regions shown. North Shields was the site of the kittiwake colony monitored by Coulson (1966), Coulson \& Thomas (1985) and Turner (2010). Other colonies occur at coastal sites north of North Shields, to Shetland, and are supposed to feed mainly within the northwestern North Sea (Wanless et al. 2007)

conditions (i.e. a 1 yr cycle) were used for nutrients along the simulated Atlantic margin. Annual totals of production were averaged over areas B2 and C2 (Fig. 5) from model gridpoints between $55.0^{\circ} \mathrm{N}$ and $60.4^{\circ} \mathrm{N}$, west of a line from $4.49^{\circ} \mathrm{E}$ (at $55.0^{\circ} \mathrm{N}$ ) to $3.02^{\circ} \mathrm{E}\left(\right.$ at $\left.60.4^{\circ} \mathrm{N}\right)$.

To obtain the co-ordinates in state space for a starting point for the trajectory, we (1) averaged CPR Calanus data for 1958 to 1962, resulting in a mean value of 25 copepods sample ${ }^{-1}$; (2) averaged simulated production for 1958 to 1962, resulting in a mean value of $137 \mathrm{~g} \mathrm{C} \mathrm{m}^{-2} \mathrm{yr}^{-1}$; (3) assumed a kittiwake breeding success of 1.4 fledglings nest ${ }^{-1}$ based on the mature stage (around 1960) of the colony reported in Coulson \& Thomas (1985). 


\section{Time-series plots}

Average net primary production simulated by GETM-ERSEM was $130 \mathrm{~g} \mathrm{C} \mathrm{m}^{-2} \mathrm{yr}^{-1}$, with $90 \%$ of values lying between 115 and 151. This is higher than the range ( 50 to $100 \mathrm{~g} \mathrm{C} \mathrm{m}^{-2} \mathrm{yr}^{-1}$ ) of results from other models and observations (Supplement 7). Values were slightly lower in the middle part of the time series (Fig. 6c), but there was no obvious long-term trend. This may be because the simulation used climatological northern boundary conditions. Heath \& Beare (2008) calculated new production from the observed spring draw-down in nutrients in each year between 1960 and 2003, and obtained higher values-implying greater inflow of Atlantic waterduring the first 2 decades.

Calanus abundance (Fig. 6b) showed an early decrease with some recovery in recent decades, perhaps associated with observed changes in planktonic communities (Beaugrand et al. 2002). The kittiwake data (Fig. 6a) also show a steady decline (from the start of the SMP time-series in 1986), possibly the result of changes in the availability of its prey fishes, in turn influenced by fisheries and by climate fluctuations (Coulson \& Thomas 1985, Furness \& Tasker 2000, Wanless et al. 2007). The agreement between the SMP data and Turner's (2010) measurement of rearing at the North Shields colony in 2000 lends confidence to combining early and recent kittiwake data.

\section{State space plot}

The data were plotted in 3 dimensions using a Matlab script and standard 3D plotting and viewing functions. Fig. 7 shows the trajectory of annual means through the state space. No transformations have been applied at this stage. There are 3 obvious features to this trajectory. First, there is much interannual variability. Second, there has been a longterm decrease in kittiwake rearing success and in Calanus abundance. Third, consequent on the second point, the system has moved a long way from the conditions ca. 1960. There is, however, no indication of sudden change from one contrasting and persisting state to another, i.e. no evidence for a regime shift as defined by deYoung et al. (2008).

Fig. 8a shows the standardized Euclidian distance (Fig. 1) of each annual point in Fig. 7 from the arbitrary 1960 'reference condition', and confirms the extent and continuity of the change. Annual scalar variability (Fig. 8b, hypothesized to be proportional to compliance and inverse resilience) was calculated as the absolute deviation from the trend-line fitted to this change. Although only the copepod data were taken from a single monitoring programme, the $11 \mathrm{yr}$ running mean (labelled 'smoothed' in Fig. 8b) suggests an initial trend of increasing variability, followed perhaps by a weak trend of a decrease. These results are presented to exemplify the state space approach rather than to test hypotheses about change,

Fig. 6. Time-series, for the study region, of values of the 3 state variables. (a) Kittiwake reproductive success (in chicks reared per nest), either from a single colony at North Shields (5 yr running mean) or from the Scottish colonies observed by the Seabird Monitoring Programme (SMP); (b) Calanus spp. abundance: annual mean numbers of $C$. finmarchicus and $C$. helgolandicus individuals per Continuous Plankton Recorder $(C P R)$ tow unit within the regions B2 and C2 (see Fig. 5); (c) simulated net primary production was that hindcast by the General Estuarine Transport-European Regional Seas Ecosystem (GETM-ERSEM) model in $\mathrm{g} C$ fixed $\mathrm{m}^{-2} \mathrm{yr}^{-1}$, averaged over the same regions
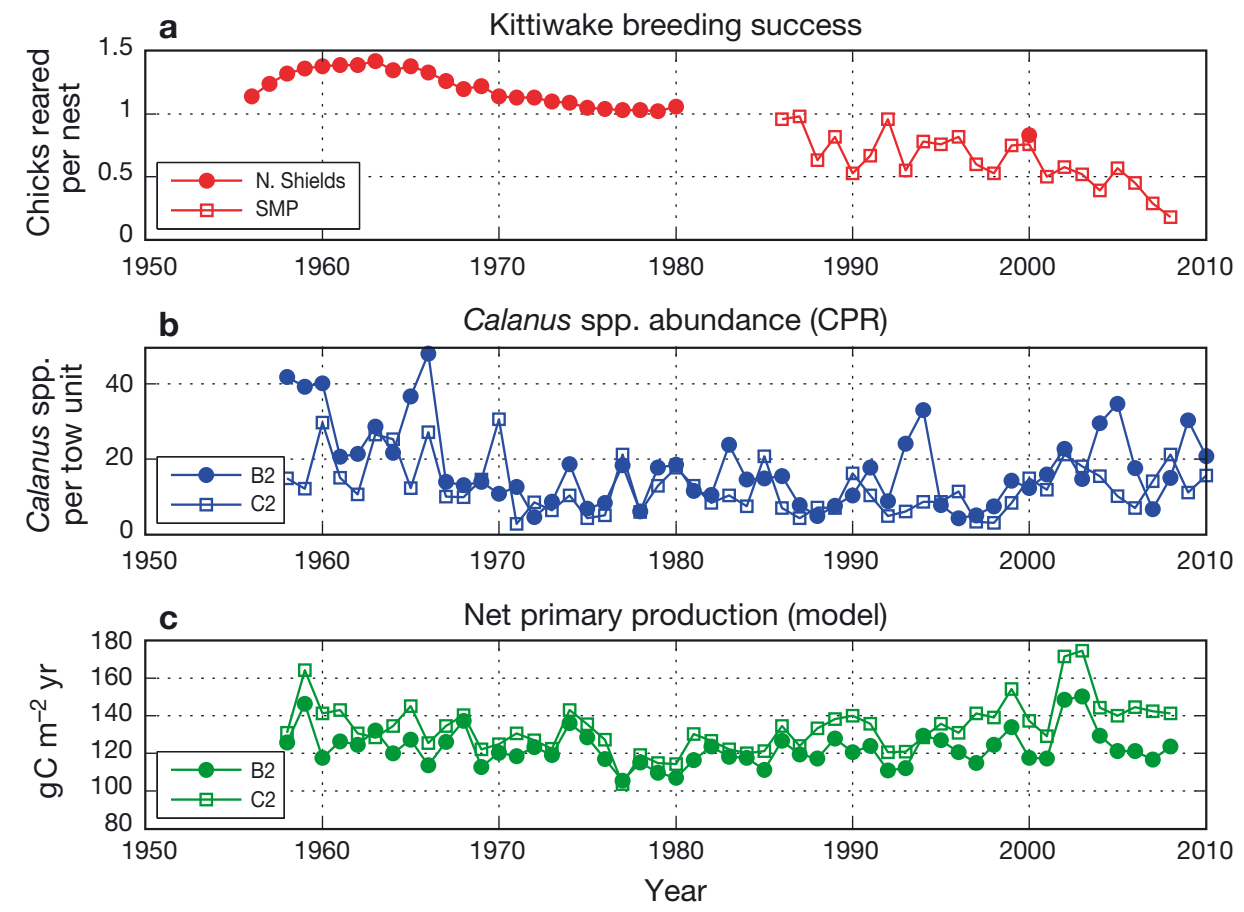


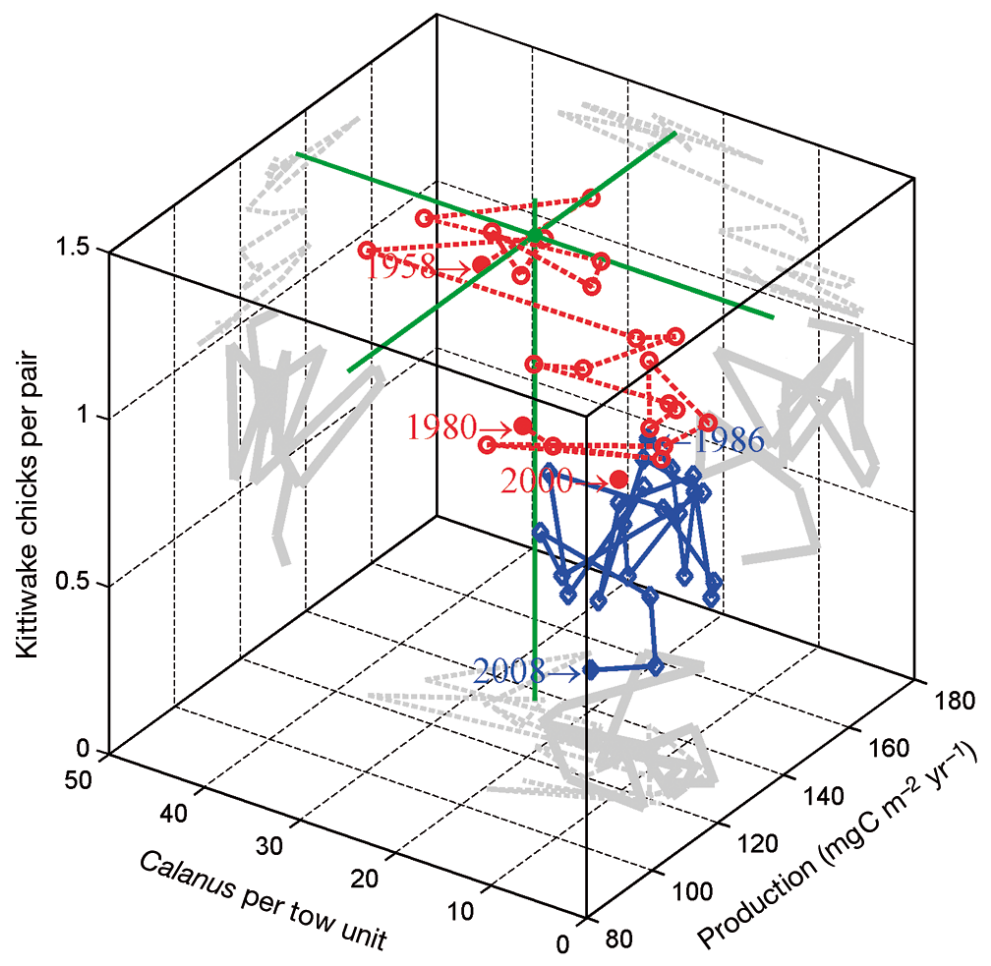

Fig. 7. State space plots of the time-series of annual values of kittiwake breeding success (chicks reared per nest), Calanus spp. abundance (copepods per tow unit of approx. $3 \mathrm{~m}^{3}$ ), and simulated primary production in the northwestern North Sea. The green lines intersect at the example's arbitrary reference point, circa 1960. The dashed red line corresponds to the time-series from 1958 until 1980 (kittiwake data from North Shields only) and the solid blue line is kittiwake data from the Seabird Monitoring Programme $(S M P)$. The grey lines plotted on the sides of the cube show the graphs for each 2 -dimensional subset of the state variables. The state of the ecosystem has changed substantially between 1960 and 2008 (i.e. there is a long-term trend); in addition, the system shows much year-to-year (medium term) variation

Fig. 8. Scalar change in ecosystem state, derived from the state space plot in Fig. 7 showing (a) time-series of Euclidian distance from arbitrary 1960 reference condition. The distance was calculated as the square root of the sum of squares of the base 10 logarithms of the difference between each variable and its reference value. The trend line is a fitted third order polynomial $\left(\mathrm{r}^{2}=0.53, \mathrm{p}<\right.$ 0.01, df =42). (b) Scatter plots of (absolute values of) annual deviation from the trend, with 11 yr running means and fitted third order polynomial $\left(r^{2}=0.17, p\right.$ $<0.01$, df $=38$; starting from $\mathrm{n}=46,4 \mathrm{df}$ used in fitting each curve). The deviation $s^{\prime}$ corresponds to the system compliance, and is interpreted as the inverse of the resistance component of resilience. Note that the earlier kittiwake data are 5 yr running means, but from one site; the later data (1987 through 2008) are annual values averaged over many sites
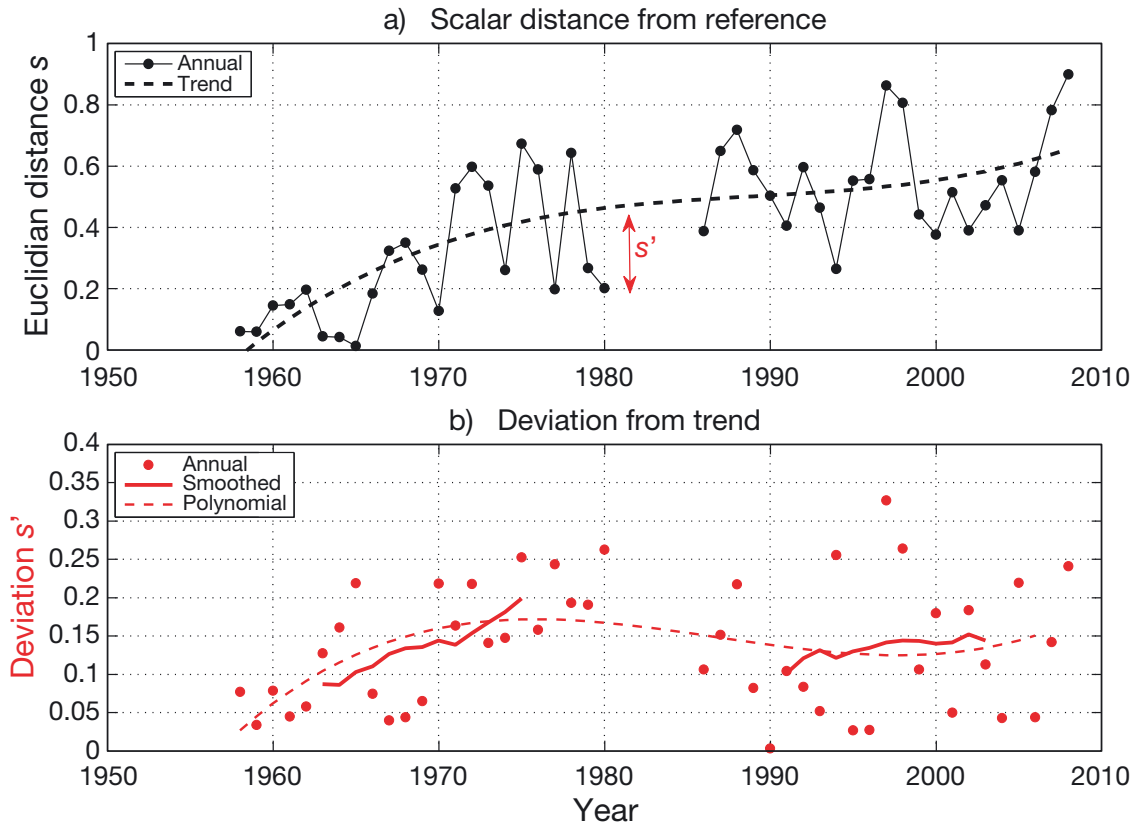

and so we have not carried out rigorous time-series analysis. Nevertheless, a third order polynomial explained a significant part of the variability in the data and confirmed the pattern in the running mean.

\section{Assessment}

The 3 state variables used in this example were intended to capture 3 elements of the trophic net- work in the North Sea. They were also chosen because adequately long time-series of each were available and sufficiently understood to explain and caveat the conclusions reached from the analysis. Clearly, 'adequately long' implies half a century or more in these waters, in order to take account of natural fluctuations and the decadal time-scales of observed ecosystem changes (Kenny et al. 2009).

Several studies have deduced a regime shift in the North Sea centred either on 1988 (Edwards et al. 
2001, Reid et al. 2001, McQuatters-Gollop et al. 2007) or on 1993 (Kenny et al. 2009). Such a shift is not evident in Fig. 7, which is more compatible with the conclusion by Spencer et al. $(2011$, p. 19) that 'changes in UK marine communities appear to be dominated by gradual trends over the last two to three decades'. However, Fig. 8b suggests increasing variability (about the long-term trend in Fig. 8a) until about 1980. If this is interpreted (Scheffer et al. 2009) as a decrease in ecosystem resilience, it would be compatible with an approach to a gradual regime shift during the 1980s.

\section{SYNTHESIS AND A LOOK FORWARDS}

\section{Holistic approach}

Marine ecosystems include co-adapted species linked through trophic networks and biogeochemical cycles, with the consequence that disturbance to some species' populations can impact on those of other species, or modify ecosystem services that depend on interactions among ecosystem components. It is necessary to understand these links, and to identify whole-ecosystem quality objectives and assessment methods, if environmental managers are to fully protect ecosystem services and ensure their sustainable use under pressure. Several integrated assessment methods have been proposed in recent years. We consider 3 examples, each with a different approach to the challenge.

Working within the same (European) policy framework as us, Borja et al. (2011) suggested an aggregative approach to GES under the MSFD. The issue here is the weights used in the combinatorial process, which must be decided by expert judgement. Halpern et al. (2012) proposed a generic 'ocean health index' assembled from public goals for marine ecosystem services. This may allow too much focus on particular uses of marine systems, even if the sustainability of such use depends on the maintenance of good ecosystem health, and it provides little insight into the functioning that underpins health. Closest to our proposed use of state space is the method used by Hemery et al. (2008), who took the first principal component from a multivariate analysis as an overall index of changing ecosystem state in the Bay of Biscay. Such use of principal component analysis (PCA) to estimate a scalar distance in a multivariable state space contrasts with our use of Euclidian distance.

Management of ecosystems requires explanation as well as measurement of change. Our contention is that a theory of ecosystem health-even if yet to be fully developed - can provide a basis for understanding ecosystem functioning and for monitoring and managing marine ecosystems in relation to their intrinsic worth as well as their value to human society. According to the systemic approach, persistence of an open system depends on the maintenance of functional integrity whilst processing throughputs of energy and materials. Resilience is the ability to maintain integrity despite changes in boundary conditions. It depends on the organization and vigour of ecosystems. Organization, which refers to ecosystem components and their interconnections, includes functional-group diversity and functional-response diversity, the occurrence of co-adapted species, and the existence of multiple and alternative trophic pathways and of stabilizing feedbacks. Vigour is the flow of energy and materials that maintains organization. Panarchy takes account of system heterogeneity on multiple scales in space and time, which may contribute to resilience.

\section{State space method}

Resilience is the crucial aspect of ecosystem health, and sustaining it should be the prime objective of ecosystem managers (Gunderson 2000), because resilient systems can maintain themselves against pressures and change. The challenge is to quantify its elements: resistance, latitude and precariousness (Walker et al. 2004). In the absence of sufficient ecological theory to compute these from directly observable properties, such as biodiversity (as relating to organization) and production (as a measure of vigour), we have proposed the use of a state space approach to track changes in ecosystem condition (Table 3). As discussed in Supplement 6, relating changes in state to changes in pressure might allow models for system compliance (the inverse of the resistance component of resilience) to be parameterised empirically. In this study, however, our focus has been on ecosystem state and its changes rather than on the causes of those changes.

Our method requires the identification of variables that define a state space and capture the most important aspects of ecosystem organization and vigour. The review in 'Organization and biodiversity' above suggested that focusing on functional diversity is most likely to provide insights into ecosystem function, and thus, ideally, that the state variables chosen for plotting should represent functional groups. The variables used in our North Sea example were some 
Table 3. Summary of the proposed method for tracking change in ecosystem state and estimating resilience

\begin{tabular}{|l|l|l|}
\hline Steps of the method & Example used in this study & Issues \\
\hline $\begin{array}{l}\text { 1. Identify (spatial extent) of } \\
\text { ecosystem }\end{array}$ & $\begin{array}{l}\text { Northwestern part of the North Sea (see } \\
\text { Fig. 5) }\end{array}$ & $\begin{array}{l}\text { Boundaries determined by natural conditions } \\
\text { or by human custom or legislation; extent of } \\
\text { trans-boundary fluxes }\end{array}$ \\
\hline $\begin{array}{l}\text { 2. Identify spatial granularity and } \\
\text { extent of repetitive temporal } \\
\text { variability, and decide how to } \\
\text { average or aggregate over these }\end{array}$ & $\begin{array}{l}\text { Treated as a single spatial unit and } \\
\text { averaged or aggregated over a year }\end{array}$ & $\begin{array}{l}\text { Granularity and hierarchy may contribute } \\
\text { through panarchy to resilience; ecosystem } \\
\text { may contain several biomes; seasonal } \\
\text { variability may be seen as organization }\end{array}$ \\
\hline 3. Select state variables & $\begin{array}{l}\text { Annual net primary production (from } \\
\text { simulation); mean annual abundance of } \\
\text { copepods Calanus spp. (from Continuous } \\
\text { Plankton Recorder [CPR] survey); kitti- } \\
\text { wake chick rearing success (mean over } \\
\text { coastal colonies supported by the marine } \\
\text { ecosystem under consideration) (see Fig. 6) }\end{array}$ & $\begin{array}{l}\text { Variables should broadly represent the } \\
\text { 'condition' of the ecosystem, including its } \\
\text { organization and vigour; they should comprise } \\
\text { time-series extending over several 'natural } \\
\text { periods' for that ecosystem }\end{array}$ \\
\hline $\begin{array}{l}\text { 4. Plot trajectory in state space } \\
\text { and calculate Euclidian (scalar) } \\
\text { distance from (arbitrary) } \\
\text { reference condition }\end{array}$ & $\begin{array}{l}\text { 3D state space plot in Fig. 7; scalar distance } \\
\text { from 1960 'reference condition' in Fig. 8a }\end{array}$ & $\begin{array}{l}\text { Euclidian distance is one method to reduce a } \\
\text { vector distance to a scalar; other options for } \\
\text { simplification of a n-dimensional trajectory } \\
\text { include extraction of principal component(s) } \\
\text { and the enumeration of points in relation to a } \\
\text { reference envelope }\end{array}$ \\
\hline $\begin{array}{l}\text { 5. Calculate medium-term } \\
\text { variability about trend in state } \\
\text { space, and use this variability as } \\
\text { proxy for (inverse) resilience }\end{array}$ & $\begin{array}{l}\text { Trend established by fitting third order } \\
\text { polynomial; variability measured as annual } \\
\text { deviation from this trend (see Fig. 8b) }\end{array}$ & $\begin{array}{l}\text { The distinction between repetitive, medium- } \\
\text { term and long-term variability; the differences } \\
\text { in natural variability amongst ecosystems }\end{array}$ \\
\hline
\end{tabular}

way from this ideal, but served to demonstrate the method. They also show that the method itself does not strongly constrain the choice of state variables.

The suggestion to plot marine ecosystem data in state-space is not new. Margalef (1978) drew a 2-D space, defined by conditions in the physico-chemical environment, to show the niches preferred by different types (lifeforms) of phytoplankter, and to theorize how the state of the phytoplankton community responded to seasonal or other changes in the physical environment. More recently, Bald et al. (2005) and Muxika et al. (2007) used state space plots, from which they extracted principal components, to characterize both the pressures on, and the ecological state of, the shallow-water benthos.

Finally, the state space method is based on a definition of ecosystem that requires identification of a region within defined boundaries. Ideally these boundaries would be natural discontinuities. In practice they are determined by management considerations, and in consequence the system thus defined may contain a patchwork of physical and chemical environments and biotic communities. In order to avoid issues resulting from such heterogeneity, we chose the comparatively homogenous northern North Sea for our example. It is smaller than the smallest region (the 'Greater North Sea') allowed as an assessment unit by the MSFD, and we have not considered issues relating to spatial patchiness and panarchy.

\section{Reference conditions}

The results reported here involved the calculation of Euclidian distance from an arbitrary reference condition, and the comparison of variability over time. This procedure is applicable to data from any type of ecosystem, irrespective of the state space coordinates of the reference condition or the system's natural variability. However, although not required by the method, the reference condition would ideally lie within a state space domain corresponding to good health and maximum resilience, and we see an important goal for quantitative ecological theory as being the specification of such domains in a variety of estuarine and coastal ecosystem types. The identification of these domains might, we think, be achieved in part through the analysis of existing time-series of marine ecosystem states, pressures, and services, and in part through the development of generic models for relationships between pressures and ecosystem states. Ideally, these models will be of sufficient generality to apply to systems of naturally low species diversity, such as those found in estuaries (Elliott \& Whitfield 2011), as well as to the more species-rich open sea ecosystems.

An interesting question concerns whether there is a unique domain of health for a given ecosystem type, i.e. under given ecohydrodynamic conditions. This would be the case for Clement's (1936) concept of a climax community and the argument (Moss 2008) 
that natural ecosystems are best adapted to their environments. It is the view taken by the WFD, which equates 'Good Ecological Status' with the structure and function of aquatic ecosystems that are similar to those of the same type under undisturbed conditions. In contrast, the view of systems as multiple interconnected networks suggests that they can exist in more than one stable (i.e. resilient and healthy) configuration (Krebs 1988). It is even possible that ecosystems that have become impoverished in species can function well and can demonstrate resilience as a result of adaptation within populations of generalist species, as may naturally be the case for estuaries (Elliott \& Whitfield 2011). The possibility of more than one domain of good ecosystem health would seem to be allowed for within the MSFD, which for GES simply requires ecosystems to 'function fully' within the constraints set by the intrinsic environmental conditions and to 'maintain their resilience to human-induced environmental change'. If each stable configuration can deliver a set of sustainable services, albeit different ones, the issue then becomes that of deciding which set is preferred by society.

\section{Data requirements}

The role of biodiversity in relation to ecosystem function, and the causes and nature of regime shifts, have become better understood as increasing amounts of data and increasing numbers and lengths of time-series have become available from a variety of ecosystems. Our proposed method also needs long time-series to track changes in system state space, to estimate changes in variability as a proxy for resilience, and to seek empirical relationships with pressure changes.

Although there is potential in remote sensing (Platt \& Sathyendranath 2008, Platt et al. 2010), multidecadal oceanic ecological datasets are rare (Edwards et al. 2010). In general, research funding is inadequate to collect sufficient data, over sufficiently long periods of time, to test hypotheses relating to changes in ecosystem health. The relevant time-scale of variability shown by our North Sea example is, at least, decadal, (see also Kenny et al. 2009). The most effective drivers of data-collection on this long timescale are (1) fisheries management, (2) conservation of protected species, and (3) environmental protection legislation - and we suggest that data collected routinely for such purposes might also be used for research into the key issues raised in this study concerning ecosystem health (Supplement 8). Although it may be that the research questions ought to influence the choice of variables observed during these programmes, we consider that the holistic approach to ecosystems should add little to a programme's overall cost, because the extra work required lies mainly in the numerical analysis exemplified in 'An example of the state space approach', above.

\section{Metaphors and models}

Data alone are insufficient for understanding and predicting changes in ecosystem health. Complex systems do not function in ways that can easily be understood by common sense, nor on spatial or temporal scales that map well to human polities and democratic political processes. Nevertheless, society needs explanations that can justify the management of human pressures that act on the holistic condition of marine coastal ecosystems. The idea of ecosystem health is, in its most general form, a way of translating complex system behaviour into a widely and intuitively comprehensible explanation. However, as Lackey (2001) and others have argued, the use of health as a metaphor is open to abuse through the covert insertion of sectional values. Thus, there is a need to describe system behaviour in terms that are scientifically sound (i.e. open to falsification) but sufficiently simple and transparent to communicate changes in system state and vulnerability to nonspecialists. That is why metaphors for system resilience have been found useful.

This is not to deny the relevance and utility of other types of models (Table 4). Simple mathematical models with 1 or 2 state variables can demonstrate bifurcations (Collie et al. 2004), the importance of trophic connectance (Vallina \& Le Quéré 2011), and the role of boundary conditions (van de Koppel et al. 2008). Complex mechanistic models (such as ERSEM; Baretta et al. 1995, Allen et al. 2001, Blackford et al. 2004) - in which the model building blocks represent functional groups, and the system can be replicated on spatial grids to include the effects of granularity - can provide detailed internal descriptions of ecosystems. ERSEM was used to provide the production data in 'An example of the state space approach', above. Improved understanding of functional diversity and functional response diversity (see 'Organization and biodiversity', above) should help in allowing such models to fully represent ecosystem processes and their adaptive responses to changes in external forcing. Complex empirical models, such as EcoPath (Pauly et al. 2000, Christensen \& Walters 2004) for 
Table 4. Examples of use of models in relation to ecosystem health

\begin{tabular}{|l|l|l|l|}
\hline Generic type of model & Epistemology & Simple model examples & Complex model examples \\
\hline $\begin{array}{l}\text { Conceptual and } \\
\text { metaphorical }\end{array}$ & $\begin{array}{l}\text { Used to explain } \\
\text { ecosystem function } \\
\text { using 'common sense' } \\
\text { analogies }\end{array}$ & $\begin{array}{l}\text { Landscape (including cliff and } \\
\text { basin) (Holling 1973, Krebs 1988, } \\
\text { Scheffer et al. 2001) and elasticity } \\
\text { (the present study) metaphors for } \\
\text { emergent properties such as } \\
\text { stability and resilience }\end{array}$ & $\begin{array}{l}\text { Analogies (such 'attractors') derived from } \\
\text { mathematical properties of systems of } \\
\text { equations (Ives \& Carpenter 2007); } \\
\text { networks (e.g. food webs based on } \\
\text { stomach contents; Hardy 1924) }\end{array}$ \\
\hline Mechanistic & $\begin{array}{l}\text { Assembled from } \\
\text { quantitative } \\
\text { hypotheses tested } \\
\text { under controlled } \\
\text { conditions-i.e. } \\
\text { simulating causation }\end{array}$ & $\begin{array}{l}\text { Lotka-Volterra and similar models } \\
\text { (and their predictions about } \\
\text { bifurcation, regime shift, etc. } \\
\text { (Collie et al. 2004, van de Koppel } \\
\text { et al. 2008, Vallina \& Le Quéré } \\
\text { 2011) }\end{array}$ & $\begin{array}{l}\text { Multi-component physically-coupled } \\
\text { ecosystem models, e.g. European Regional } \\
\text { Seas Ecosystem Model (ERSEM: Baretta et } \\
\text { al. 1995, Blackford et al. 2004); complex } \\
\text { model parameterization difficulties } \\
\text { discussed by Cropp \& Norbury (2013) }\end{array}$ \\
\hline $\begin{array}{l}\text { Empirical } \\
\text { Fitted to data (e.g. by } \\
\text { squimizing sum of } \\
\text { likelihood) -i.e. } \\
\text { summarizing } \\
\text { correlation }\end{array}$ & $\begin{array}{l}\text { Statistical: regressions and trends; } \\
\text { by-analogy models such as that } \\
\text { for compliance corresponding to } \\
\text { elasticity in the analogue of a } \\
\text { mechanical spring }\end{array}$ & $\begin{array}{l}\text { MultiVariate Analysis (MVA) used for } \\
\text { detecting regime shift; Bayesian belief } \\
\text { networks (Langmead et al. 2009); network } \\
\text { models fitted by parameter estimation } \\
\text { (Ecopath: Pauly et al. 2000, Christensen \& } \\
\text { Walters 2004; Structural Equation } \\
\text { Modelling (SEM): Alsterberg et al. 2013) }\end{array}$ \\
\hline
\end{tabular}

food-webs, are useful for analysing incomplete ecosystem data in terms of organization and vigour (Ulanowicz \& Kay 1991). 'End-to-End', or 'E2E' models are viewed both as 'virtual worlds' and as fisheries management tools (Steele et al. 2013), and are often empirical-mechanistic hybrids. There is much work to be done: both mechanistic and empirical models of marine ecosystems have so far proven more useful for exploring change than for defining a state of good health. However, new methods allow analysis of complex ecosystem models. For example, Cropp \& Norbury (2013) consider how to find useful models amongst the multitude of possible models in the 'Library of Lotka', and Alsterberg et al. (2013) used Structural Equation Modelling (SEM) to disentangle multiple links between causes and effects in results from experiments with benthic mesocosms.

\section{CONCLUSIONS}

The concept of ecosystem health can be used to generate holistic methodologies for the monitoring and management of marine ecosystems, but is itself a subject of debate. We have attempted to bring the discussion up to date and to suggest a definition of health that can be used with both empirical and systemic perspectives of ecosystems. In a European context, we suggest that a condition of good health in estuarine and coastal marine ecosystems is implied by the 'Good Ecological Status' of the WFD and the 'Good Environmental Status' of the MSFD. Both Directives have a holistic aim, but the MSFD appears to be one of the first laws requiring a holistic picture of marine ecosystems because its 'qualitative descriptors' can be read as incorporating all the aspects of organization and vigour that are discussed here.

However, a potential risk is that the MSFD assessments will be summed over descriptors, and so fail to provide warning of changes in the general health of the ecosystems in question. The rules for combining multiple indicators have not yet been agreed for the MSFD, but if the 'one-out, all-out' rule of the WFD is used for the MSFD with its greater number of descriptors and indicators, then there will be a greater chance of failure (Borja \& Rodríguez 2010). What we have proposed is a method by which results from monitoring of individual descriptors can be combined to make a higher-order assessment of system condition. Although state space visualizations of system state have been widely used in analyses of model systems, there is an element of novelty in our use of such visualizations for a real marine system, and in the use of Euclidian distance to track change and variability. Most other studies have used a statistical multivariate analysis method to summarize trends in multiple variables. Our approach (Table 3) is, we contend, more transparent and also better able to lead to the identification of stable and healthy ecosystem configurations.

Acknowledgements. The work described here was in part funded by UK Defra contract ME5302 to Cefas, and in part by the institutions of the non-Cefas authors. Opinions expressed here are those of the authors and not necessarily of Defra or the institutes to which authors are affiliated. CPR data were provided by D. Johns from the CPR survey database at the Sir Alister Hardy Centre for Ocean Study (SAHFOS) in Plymouth. 


\section{LITERATURE CITED}

Allen JI, Blackford J, Holt J, Proctor R, Ashworth M, Siddorn J (2001) A highly spatially resolved ecosystem model for the North West European Continental Shelf. Sarsia 86: 423-440

Alsterberg C, Eklöf JS, Gamfeldt L, Havenhand JN, Sundbäck K (2013) Consumers mediate the effects of experimental ocean acidification and warming on primary producers. Proc Natl Acad Sci USA 110:8603-8608

Atkins JP, Burdon D, Elliott M, Gregory AJ (2011) Management of the marine environment: integrating ecosystem services and societal benefits with the DPSIR framework in a systems approach. Mar Pollut Bull 62:215-226

> Aubry A, Elliott M (2006) The use of environmental integrative indicators to assess seabed disturbance in estuaries and coasts: application to the Humber Estuary, UK. Mar Pollut Bull 53:175-185

Bald J, Borja A, Muxika I, Franco J, Valencia V (2005) Assessing reference conditions and physico-chemical status according to the European Water Framework Directive: a case-study from the Basque Country (Northern Spain). Mar Pollut Bull 50:1508-1522

Barbier EB, Hacker SD, Koch EW, Stier AC, Silliman BR (2012) Estuarine and coastal ecosystems and their services. In: van den Belt M, Costanza R (eds) Treatise on estuarine and coastal science, Vol 12: Ecological economics of estuaries and coasts. Elsevier, London, p 109-127

- Baretta JW, Ebenhöh W, Ruardij P (1995) The European Regional Seas Ecosystem Model, a complex marine ecosystem model. Neth J Sea Res 33:233-246

> Baretta-Bekker JG, Baretta JW (1997) European regional seas ecosystem model II. J Sea Res 38:169-436

Barnes H (1952) The use of transformations in marine biological statistics. ICES J Mar Sci 18:61-71

> Beaugrand G (2004) The North Sea regime shift: evidence, causes, mechanisms and consequences. Prog Oceanogr 60:245-262

Beaugrand G, Reid PC, Ibañez F, Lindley JA, Edwards M (2002) Reorganization of North Atlantic marine copepod biodiversity and climate. Science 296:1692-1694

Bengtsson J (1998) Which species? What kind of diversity? Which ecosystem function? Some problems in studies of relations between biodiversity and ecosystem function. Appl Soil Ecol 10:191-199

Berkes F, Folke C (eds) (1998) Linking social and ecological systems: management practices and social mechanisms for building resilience. Cambridge University Press, Cambridge

Blackford JC, Allen JI, Gilbert FJ (2004) Ecosystem dynamics at six contrasting sites: a generic modelling study. J Mar Syst 52:191-215

> Borja Á, Rodríguez JG (2010) Problems associated with the 'one-out, all-out' principle, when using multiple ecosystem components in assessing the ecological status of marine waters. Mar Pollut Bull 60:1143-1146

Borja Á, Elliott M, Carstensen J, Heiskanen AS, van de Bund W (2010) Marine management-towards an integrated implementation of the European Marine Strategy Framework and the Water Framework Directives. Mar Pollut Bull 60:2175-2186

Borja Á, Galparsoro I, Irigoien X, Iriondo A and others (2011) Implementation of the European Marine Strategy Framework Directive: a methodological approach for the assessment of environmental status, from the Basque
Country (Bay of Biscay). Mar Pollut Bull 62:889-904

> Borja Á, Dauer DM, Grémare A (2012) The importance of setting targets and reference conditions in assessing marine ecosystem quality. Ecol Indic 12:1-7

Botkin DB (1990) Discordant harmonies: a new ecology for the twenty-first century. Oxford University Press, New York, NY

Boulding KE (1956) General Systems Theory: the skeleton of science. Manage Sci 2:197-208

> Brown JR, Gowen RJ, McLusky DS (1987) The effect of salmon farming on the benthos of a Scottish sea loch. J Exp Mar Biol Ecol 109:39-51

Buchsbaum R, Pederson J, Robinson WE (eds) (2005) The decline of fisheries resources in New England: evaluating the impact of overfishing, contamination, and habitat degradation. MIT Sea Grant College Program, Cambridge, MA

> Bundy A, Fanning LP (2005) Can Atlantic cod (Gadus morhua) recover? Exploring trophic explanations for the non-recovery of the cod stock on the eastern Scotian Shelf, Canada. Can J Fish Aquat Sci 62:1474-1489

Burchard H, Bolding K (2002) GETM: a general estuarine transport model. Scientific documentation. Technical report EUR 20253 EN, European Commission, Ispra

Caroni R, van de Bund W, Clarke R, Johnson R (2013) Combination of multiple biological quality elements into waterbody assessment of surface waters. Hydrobiologia 704:437-451

Christensen V (1995) Ecosystem maturity-towards quantification. Ecol Model 77:3-32

Christensen V, Pauly D (1992) ECOPATH II-a software for balancing steady-state ecosystem models and calculating network characteristics. Ecol Model 61:169-185

Christensen V, Walters CJ (2004) Ecopath with Ecosim: methods, capabilities and limitations. Ecol Model 172: 109-139

Christian RR, Voss CM, Bondavalli C, Viaroli P and others (2010) Ecosystem health indexed through networks of nitrogen cycling. In: Kennish MJ, Paerl HW (eds) Coastal lagoons: critical habitats of environmental change. CRC Press, Boca Raton, FL, p 73-90

Clements FE (1916) Plant succession: an analysis of the development of vegetation. Publication No. 242, Carnegie Institution of Washington, Washington, DC

> Clements FE (1936) Nature and structure of the climax. J Ecol 24:252-284

Collie JS, Richardson K, Steele JH (2004) Regime shifts: can ecological theory illuminate the mechanisms? Prog Oceanogr 60:281-302

COM (European Commission) (2010) Commission Decision 2010/477/EU of 1 September 2010 on criteria and methodological standards on good environmental status of marine waters. Official Journal of the European Union L232:14-24

Costanza R (1992) Towards an operational definition of health. In: Costanza R, Norton B, Haskell BD (eds) Ecosystem health: new goals for environmental management. Island Press, Washington, DC, p 239-256

- Costanza R, Mageau M (1999) What is a healthy ecosystem? Aquat Ecol 33:105-115

> Costanza R, d'Arges R, de Groot RS, Farber S and others (1997) The value of the world's ecosystem services and natural capital. Nature 387:253-260

Coulson JC (1966) The influence of the pair-bond and age on the breeding biology of the kittiwake gull Rissa tri- 
dactyla. J Anim Ecol 35:269-279

Coulson JC, Thomas CS (1985) Changes in the biology of the kittiwake Rissa tridactyla: a 31-year study of a breeding colony. J Anim Ecol 54:9-26

Cropp R, Norbury J (2013) Modelling plankton ecosystems and the Library of Lotka. J Mar Syst 125:3-13

Crossland CJ, Kremer HH, Lindeboom HJ, Marshall Crossland JI, Le Tissier MDA (eds) (2005) Coastal fluxes in the Anthropocene: the land-ocean interactions in the coastal zone project of the international geosphere-biosphere programme. Springer-Verlag, Berlin

Crutzen PJ, Stoermer EF (2000) The 'Anthropocene'. Global Change Newsl 41:17-18

Cuddington K (2001) The "balance of nature" metaphor and equilibrium in population ecology. Biol Philos 16:463-479

Dakos V, van Nes EH, Donangelo R, Fort H, Scheffer M (2010) Spatial correlation as leading indicator of catastrophic shifts. Theor Ecol 3:163-174

Davis MA, Slobodkin LB (2004) The science and values of restoration ecology. Restor Ecol 12:1-3

deYoung B, Barange M, Beaugrand G, Harris R, Perry RI, Scheffer M, Werner F (2008) Regime shifts in marine ecosystems: detection, prediction and management. Trends Ecol Evol 23:402-409

> Dippner JW, Krause M (2013) Continuous plankton recorder underestimates zooplankton abundance. J Mar Syst 111112:263-268

> Duarte CM, Conley DJ, Carstensen J, Sánchez-Camacho M (2009) Return to Neverland: shifting baselines affect eutrophication restoration targets. Estuaries Coasts 32: 29-36

$>$ Ducrotoy JP, Elliott M (2008) The science and management of the North Sea and the Baltic Sea: natural history, present threats and future challenges. Mar Pollut Bull 57: $8-21$

> Dunne JA, Williams RJ, Martinez ND (2002) Food-web structure and network theory: the role of connectance and size. Proc Natl Acad Sci USA 99:12917-12922

Edwards M, Reid PC, Planque B (2001) Long-term and regional variability of phytoplankton biomass in the northeast Atlantic, 1960-95. ICES J Mar Sci 58:39-49

Edwards M, Beaugrand G, Hays GC, Koslow JA, Richardson AJ (2010) Multi-decadal oceanic ecological datasets and their application in marine policy and management. Trends Ecol Evol 25:602-610

- Elliott M (2011) Marine science and management means tackling exogenic unmanaged pressures and endogenic managed pressures-a numbered guide. Mar Pollut Bull 62:651-655

Elliott M, Quintino V (2007) The Estuarine Quality Paradox, Environmental Homeostasis and the difficulty of detecting anthropogenic stress in naturally stressed areas. Mar Pollut Bull 54:640-645

Elliott M, Whitfield AK (2011) Challenging paradigms in estuarine ecology and management. Estuar Coast Shelf Sci 94:306-314

Elliott M, Burdon D, Hemingway KL, Apitz SE (2007) Estuarine, coastal and marine ecosystem restoration: confusing management and science-a revision of concepts. Estuar Coast Shelf Sci 74:349-366

> Estes JA, Duggins DO (1995) Sea otters and kelp forests in Alaska: generality and variation in a community ecological paradigm. Ecol Monogr 65:75-100

Estes JA, Danner EM, Doak DF, Konar B and others (2004) Complex trophic interactions in kelp forest ecosystems.
Bull Mar Sci 74:621-638

Fogarty MJ, Murawski SA (1998) Large-scale disturbance and the structure of marine systems: fishery impacts on Georges Bank. Ecol Appl 8:S6-S22

Foley MM, Halpern BS, Micheli F, Armsby MH and others (2010) Guiding ecological principles for marine spatial planning. Mar Policy 34:955-966

Folke C, Carpenter S, Walker B, Scheffer M, Elmqvist T, Gunderson L, Holling CS (2004) Regime shifts, resilience, and biodiversity in ecosystem management. Annu Rev Ecol Evol Syst 35:557-581

Furness RW, Tasker ML (2000) Seabird-fishery interactions: quantifying the sensitivity of seabirds to reductions in sandeel abundance, and identification of key areas for sensitive seabirds in the North Sea. Mar Ecol Prog Ser 202:253-264

> Garmendia M, Revilla M, Bald J, Franco J and others (2011) Phytoplankton communities and biomass size structure (fractionated chlorophyll "a"), along trophic gradients of the Basque coast (northern Spain). Biogeochemistry 106: 243-263

- Gleason HA (1926) The individualistic concept of the plant association. Bull Torrey Bot Club 53:7-26

Gowen RJ, Tett P, Smayda TJ (2012) Phytoplankton and the balance of nature: an opinion. Estuar Coast Shelf Sci 113: 317-323

Gray JS, Elliott M (2009) Ecology of marine sediments: science to management. Oxford University Press, Oxford

Green R, Chapman PM (2011) The problem with indices. Mar Pollut Bull 62:1377-1380

Gunderson LH (2000) Ecological resilience-in theory and application. Annu Rev Ecol Syst 31:425-439

Gunderson LH, Holling CS (eds) (2002) Panarchy: understanding transformations in human and ecological systems. Island Press, Washington, DC

Habermas J (1984) The theory of communicative action. Vol 1: Reason and the rationalization of society. Beacon Press, Boston, MA

Halpern BS, Longo C, Hardy D, McLeod KL and others (2012) An index to assess the health and benefits of the global ocean. Nature 488:615-620

Harding LE (1992) Measures of marine environmental quality. Mar Pollut Bull 25:23-27

Hardy AC (1924) The herring in relation to its animate environment. Part I. The food and feeding habits of the herring with special reference to the east coast of England. Fish Invest II 7(3):1-53

> Hare SR, Mantua NJ (2000) Empirical evidence for North Pacific regime shifts in 1977 and 1989. Prog Oceanogr 47: 103-145

Hastings A (1996) Population biology: concepts and models. Springer, New York, NY

$>$ Heath MR, Beare DJ (2008) New primary production in northwest European shelf seas, 1960-2003. Mar Ecol Prog Ser 363:183-203

Hemery G, D'Amico F, Castege I, Dupont B, D'Elbee J, Lalanne Y, Mouches C (2008) Detecting the impact of oceano-climatic changes on marine ecosystems using a multivariate index: the case of the Bay of Biscay (North Atlantic-European Ocean). Glob Change Biol 14:27-38

Hering D, Borja Á, Carstensen J, Carvalho L and others (2010) The European Water Framework Directive at the age of 10: a critical review of the achievements with recommendations for the future. Sci Total Environ 408: 4007-4019 
Holling CS (1973) Resilience and stability of ecological systems. Annu Rev Ecol Syst 4:1-23

Holling CS (2004) From complex regions to complex worlds. Ecol Soc 9:11

> Hooper DU, Chapin FS, Ewel JJ, Hector A and others (2005) Effects of biodiversity on ecosystem functioning: a consensus of current knowledge. Ecol Monogr 75:3-35

Hox JJ, Bechger TM (1998) An introduction to structural equation modeling. Family Sci Rev 11:354-373

Hughes TP, Bellwood DR, Folke C, Steneck RS, Wilson J (2005) New paradigms for supporting the resilience of marine ecosystems. Trends Ecol Evol 20:380-386

Hurlbert SH (1971) The nonconcept of species diversity: a critique and alternative parameters. Ecology 52:577-586

> Hutchinson GE (1957) Concluding remarks. Cold Spring Harb Symp Quant Biol 22:415-427

$>$ Hutchinson GE (1961) The paradox of the plankton. Am Nat 95:137-145

Hutchinson GE (1965) The ecological theater and the evolutionary play. Yale University Press, New Haven, CT

> Ignatiades L, Gotsis-Skretas O, Pagou K, Krasakopoulou E (2009) Diversification of phytoplankton community structure and related parameters along a large-scale longitudinal east-west transect of the Mediterranean Sea. J Plankton Res 31:411-428

> Ives AR, Carpenter SR (2007) Stability and diversity of ecosystems. Science 317:58-62

> Jackson JBC, Kirby MX, Berger WH, Bjorndal KA and others (2001) Historical overfishing and the recent collapse of coastal ecosystems. Science 293:629-637

JNCC (Joint Nature Conservation Committee) (2011) Seabird monitoring programme. jncc.defra.gov.uk/page1550 (accessed Nov 2011)

Johnson CW (2006) What are emergent properties and how do they affect the engineering of complex systems? Reliab Eng Syst Saf 91:1475-1481

> Johnson MTJ, Stinchcombe JR (2007) An emerging synthesis between community ecology and evolutionary biology. Trends Ecol Evol 22:250-257

Kenny AJ, Skjoldal HR, Engelhard GH, Kershaw PJ, Reid JB (2009) An integrated approach for assessing the relative significance of human pressures and environmental forcing on the status of Large Marine Ecosystems. Prog Oceanogr 81:132-148

Krebs CJ (1988) The message of ecology. Harper \& Row, New York, NY

Künitzer A, Basford D, Craeymeersch JA, Dewarumez JM and others (1992) The benthic infauna of the North Sea: species distribution and assemblages. ICES J Mar Sci 49: 127-143

- Lackey RT (2001) Values, policy, and ecosystem health. Bioscience 51:437-443

> Langmead O, McQuatters-Gollop A, Mee LD, Friedrich J and others (2009) Recovery or decline of the northwestern Black Sea: a societal choice revealed by socio-ecological modelling. Ecol Model 220:2927-2939

Lenhart HJ, Mills DK, Baretta-Bekker H, van Leeuwen SM and others (2010) Predicting the consequences of nutrient reduction on the eutrophication status of the North Sea. J Mar Syst 81:148-170

Lenton TM (2013) What early warning systems are there for environmental shocks? Environ Sci Policy 27 (Suppl 1): S60-S75

Lindeman RA (1942) The trophic-dynamic aspect of ecology. Ecology 23:399-417
Lovelock JE, Margulis L (1976) Atmospheric homeostasis by and for the biosphere: the gaia hypothesis. Tellus 26:2-10

Luiten H (1999) A legislative view on science and predictive models. Environ Pollut 100:5-11

MacArthur RH (1957) On the relative abundance of bird species. Proc Natl Acad Sci USA 43:293-295

Mageau MT, Costanza R, Ulanowicz RE (1995) The development and initial testing of a quantitative assessment of ecosystem health. Ecosyst Health 1:201-213

Magurran AE (2004) Measuring biological diversity. Blackwell Science, Oxford

Margalef R (1978) Life forms of phytoplankton as survival alternatives in an unstable environment. Oceanol Acta 1: 493-509

May RM (1977) Thresholds and breakpoints in ecosystems with a multiplicity of stable states. Nature 269:471-477

McGill BJ, Etienne RS, Gray JS, Alonso D and others (2007) Species abundance distributions: moving beyond single prediction theories to integration within an ecological framework. Ecol Lett 10:995-1015

McLusky DS, Elliott M (2004) The estuarine ecosystem; ecology, threats and management, 3rd edn. Oxford University Press, Oxford

McQuatters-Gollop A, Raitsos DE, Edwards M, Pradhan Y, Mee LD, Lavender SJ, Attrill MJ (2007) A long-term chlorophyll data set reveals regime shift in North Sea phytoplankton biomass unconnected to nutrient trends. Limnol Oceanogr 52:635-648

Millennium Ecosystem Assessment (2005) Ecosystems and human well-being: biodiversity synthesis. World Resources Institute, Washington, DC

Mitchell PI, Newton SF, Ratcliffe N, Dunn TE (eds) (2004) Seabird populations of Britain and Ireland: results of the Seabird 2000 census (1998-2002). T \& AD Poyser, London

Moss B (2008) The Water Framework Directive: total environment or political compromise? Sci Total Environ 400: 32-41

> Muxika I, Borja Á, Bald J (2007) Using historical data, expert judgement and multivariate analysis in assessing reference conditions and benthic ecological status, according to the European Water Framework Directive. Mar Pollut Bull 55:16-29

> Nickell LA, Black KD, Hughes DJ, Overnell J and others (2003) Bioturbation, sediment fluxes and benthic community structure around a salmon cage farm in Loch Creran, Scotland. J Exp Mar Biol Ecol 285-286:221-233

Nyström M, Folke C, Moberg F (2000) Coral reef disturbance and resilience in a human-dominated environment. Trends Ecol Evol 15:413-417

O'Connor T, Wong HY (2009) Emergent properties. In: Zalta EN (ed) The Stanford encyclopedia of philosophy. http:// plato.stanford.edu/archives/spr2009/entries/propertiesemergent/

Odum EP (1969) The strategy of ecosystem development. Science 164:262-270

$>$ Odum EP (1985) Trends expected in stressed ecosystems. Bioscience 35:419-422

> Pauly D, Christensen V, Walters C (2000) Ecopath, Ecosim, and Ecospace as tools for evaluating ecosystem impact of fisheries. ICES J Mar Sci 57:697-706

> Pearson TH, Barnett PRO (1987) Long-term changes in benthic populations in some West European coastal areas. Estuar Coast 10:220-226

Pearson TH, Rosenberg R (1976) A comparative study of the effects on the marine environment of wastes from 
cellulose industries in Scotland and Sweden. Ambio 5: $77-79$

Petersen JK, Hansen JW, Laursen MB, Clausen P, Carstensen J, Conley DJ (2008) Regime shift in a coastal marine ecosystem. Ecol Appl 18:497-510

Peterson W (1998) Life cycle strategies of copepods in coastal upwelling zones. J Mar Syst 15:313-326

> Pingree RD, Griffiths DK (1978) Tidal fronts on the shelf seas around the British Isles. J Geophys Res 83:4615-4622

Pinker S (2007) The stuff of thought: language as a window into human nature. Penguin, London

Platt T, Sathyendranath S (2008) Ecological indicators for the pelagic zone of the ocean from remote sensing. Remote Sens Environ 112:3426-3436

Platt T, Sathyendranath S, White GN III, Fuentes-Yaco C, Zhai L, Devred E, Tang C (2010) Diagnostic properties of phytoplankton time series from remote sensing. Estuar Coast 33:428-439

Post DM, Palkovacs EP (2009) Eco-evolutionary feedbacks in community and ecosystem ecology: interactions between the ecological theatre and the evolutionary play. Phil Trans R Soc B 364:1629-1640

- Racault MF, Le Quéré C, Buitenhuis E, Sathyendranath S, Platt T (2012) Phytoplankton phenology in the global ocean. Ecol Indic 14:152-163

Reid PC, Borges MD, Svendsen E (2001) A regime shift in the North Sea circa 1988 linked to changes in the North Sea horse mackerel fishery. Fish Res 50:163-171

Reid PC, Colebrook JM, Matthews JBL, Aiken J, Team CPR (2003) The Continuous Plankton Recorder: concepts and history, from Plankton Indicator to undulating recorders. Prog Oceanogr 58:117-173

Richardson AJ, Walne AW, John AWG, Jonas TD and others (2006) Using continuous plankton recorder data. Prog Oceanogr 68:27-74

Rodhe J (1998) The Baltic and North Seas: a processoriented review of the physical oceanography. In: Robinson AR, Brink KH (eds) The sea, Vol 11. John Wiley \& Sons, New York, NY, p 699-732

Rodhe J, Tett P, Wulff F (2006) The Baltic and North Seas: a regional review of some important physical-chemicalbiological interaction processes. In: Robinson AR, Brink KH (eds) The sea, Vol 14B. Harvard University Press, Cambridge, MA, p 1033-1075

Rose GA (2003) Fisheries resources and science in Newfoundland and Labrador: an independent assessment. Royal Commission on Renewing and Strengthening Our Place in Canada, St. John's

Ruardij P, Van Raaphorst W (1995) Benthic nutrient regeneration in the ERSEM ecosystem model of the North Sea. Neth J Sea Res 33:453-483

Salihoglu B, Neuer S, Painting S, Murtugudde R and others (2013) Bridging marine ecosystem and biogeochemistry research: lessons and recommendations from comparative studies. J Mar Syst 109-110:161-175

Scheffer M, Carpenter S, Foley JA, Folke C, Walker B (2001) Catastrophic shifts in ecosystems. Nature 413: 591-596

Scheffer M, Rinaldi S, Huisman J, Weissing FJ (2003) Why plankton communities have no equilibrium: solutions to the paradox. Hydrobiologia 491:9-18

Scheffer M, Bascompte J, Brock WA, Brovkin V and others (2009) Early-warning signals for critical transitions. Nature 461:53-59

Scheffer M, Carpenter SR, Lenton TM, Bascompte J and others (2012) Anticipating critical transitions. Science 338:344-348

Schrödinger E (1944) What is life? Cambridge University Press, Cambridge

Shannon CE (1948) A mathematical theory of communication. Bell Syst Tech J 27:379-423, 623-656

Sinclair M (1987) Marine populations: an essay on population regulation and speciation. University of Washington Press, Seattle, WA

Sinclair M, Iles TD (1989) Population regulation and speciation in the oceans. J Cons Int Explor Mer 45:165-175

Slobodkin LB (1962) Growth and regulation of animal populations. Holt, Rinehart \& Winston, New York, NY

Smith RL (1992) Elements of ecology, 3rd edn. Harper Collins, New York, NY

Spencer M, Birchenough SNR, Mieszkowska N, Robinson LA and others (2011) Temporal change in UK marine communities: trends or regime shifts? Mar Ecol 32(Suppl 1):10-24

Spieles DJ (2010) The ecosystem idea and ideal. In: Protected land: disturbance, stress and American ecosystem management. Springer, New York, NY, p 17-35

Steele JH, Aydin K, Gifford DJ, Hofmann EE (2013) Construction kits or virtual worlds; management applications of E2E models. J Mar Syst 109-110:103-108

Steneck RS, Wilson JA (2010) A fisheries play in an ecosystem theater: challenges of managing ecological and social drivers of marine fisheries at multiple spatial scales. Bull Mar Sci 86:387-411

Steneck RS, Hughes TP, Cinner JE, Adger WN and others (2011) Creation of a gilded trap by the high economic value of the Maine lobster fishery. Conserv Biol 25: 904-912

Tansley AG (1935) The use and abuse of vegetational concepts and terms. Ecology 16:284-307

Tett P, Joint I, Purdie D, Baars M and others (1993) Biological consequences of tidal stirring gradients in the North Sea. Philos Trans R Soc Lond A 343:493-508

Tett P, Gowen R, Mills D, Fernandes T and others (2007) Defining and detecting undesirable disturbance in the context of marine eutrophication. Mar Pollut Bull 55: 282-297

- Tett P, Carreira C, Mills DK, van Leeuwen S, Foden J, Bresnan E, Gowen RJ (2008) Use of a Phytoplankton Community Index to assess the health of coastal waters. ICES J Mar Sci 65:1475-1482

Tett P, Sandberg A, Mette A, Bailly D and others (2013) Perspectives of social and ecological systems. In: Mokness E, Dahl E, Støttrup JG (eds) Global challenges in integrated coastal zone management. John Wiley \& Sons, Chichester, p 229-243

Thurstan RH, Roberts CM (2010) Ecological meltdown in the Firth of Clyde, Scotland: two centuries of change in a coastal marine ecosystem. PLoS ONE 5:e11767

- Tokeshi M (1993) Species abundance patterns and community structure. Adv Ecol Res 24:111-186

Turner DM (2010) Counts and breeding success of Blacklegged Kittiwakes Rissa tridactyla nesting on man-made structures along the River Tyne, northeast England, 1994-2009. Seabird 23:111-126

> Ulanowicz RE (1979) Complexity, stability and self-organization in natural communities. Oecologia 43:295-298

> Ulanowicz RE (2009) The dual nature of ecosystem dynamics. Ecol Model 220:1886-1892

Ulanowicz RE, Kay JJ (1991) A package for the analysis 
of ecosystem flow networks. Environ Softw 6:131-142

Urban MC, Skelly DK (2006) Evolving metacommunities: towards an evolutionary perspective on metacommunities. Ecology 87:1616-1626

Vallina SM, Le Quéré C (2011) Stability of complex food webs: resilience, resistance and the average interaction strength. J Theor Biol 272:160-173

van de Koppel J, Tett P, Naqvi W, Oguz T and others (2008) Threshold effects in semi-enclosed marine ecosystems. In: Urban ER Jr, Sundby B, Malanotte-Rizzoli P, Melillo JM (eds) Watersheds, bays and bounded seas: the science and management of semi-enclosed marine systems. Island Press, Washington, DC, p 31-47

van Leeuwen SM, van der Molen J, Ruardij P, Fernand L, Jickells T (2013) Modelling the contribution of deep chlorophyll maxima to annual primary production in the North Sea. Biogeochemistry 113:137-152

Varela FJV, Maturana H (1980) Autopoiesis and cognition: the realization of the living. Reidel, Boston, MA

> Vezzulli L, Reid PC (2003) The CPR survey (1948-1997): a gridded database browser of plankton abundance in the North Sea. Prog Oceanogr 58:327-336

von Bertalanffy L (1968) General Systems Theory: founda-

Editorial responsibility: Christine Paetzold,

Oldendorf/Luhe, Germany tions, development, applications. George Braziller, New York, NY

von Bertalanffy L (1972) The history and status of General Systems Theory. Acad Manage J 15:407-426

Walker B, Holling CS, Carpenter SR, Kinzig A (2004) Resilience, adaptability and transformability in socialecological systems. Ecol Soc 9:5 [online] www.ecologyandsociety.org/vol9/iss2/art5

Wanless S, Frederiksen M, Daunt F, Scott BE, Harris MP (2007) Black-legged kittiwakes as indicators of environmental change in the North Sea: evidence from longterm studies. Prog Oceanogr 72:30-38

Warner AJ, Hays GC (1994) Sampling by the continuous plankton recorder survey. Prog Oceanogr 34:237-256

> Washington HG (1984) Diversity, biotic and similarity indices: a review with special relevance to aquatic ecosystems. Water Res 18:653-694

Weijerman M, Lindeboom H, Zuur AF (2005) Regime shifts in marine ecosystems of the North Sea and Wadden Sea. Mar Ecol Prog Ser 298:21-39

Winterhalder K, Clewell AF, Aronson J (2004) Values and science in ecological restoration-a response to Davis and Slobodkin. Restor Ecol 12:4-7

Submitted: April 2, 2013; Accepted: August 27, 2013

Proofs received from author(s): October 20, 2013 